\title{
The Application of a One-Dimensional Position-Sensitive Detector to a Kratky Small-Angle X-Ray Camera
}

\author{
T. P. Russell \\ R. S. Stein \\ M. K. Kopp \\ R. E. Zedler \\ R. W. Hendricks \\ J. S. Lin
}




\section{DISCLAIMER}

This report was prepared as an account of work sponsored by an agency of the United States Government. Neither the United States Government nor any agency Thereof, nor any of their employees, makes any warranty, express or implied, or assumes any legal liability or responsibility for the accuracy, completeness, or usefulness of any information, apparatus, product, or process disclosed, or represents that its use would not infringe privately owned rights. Reference herein to any specific commercial product, process, or service by trade name, trademark, manufacturer, or otherwise does not necessarily constitute or imply its endorsement, recommendation, or favoring by the United States Government or any agency thereof. The views and opinions of authors expressed herein do not necessarily state or reflect those of the United States Government or any agency thereof. 


\section{DISCLAIMER}

Portions of this document may be illegible in electronic image products. Images are produced from the best available original document. 


\section{Printed in the United States of America. Available from}

National Technical Information Service

U.S. Department of Commerce 5285 Port Royal Road, Springfield, Virginia 22161

Price: Printed Copy $\$ 5.25$; Microfiche $\$ 3.00$

This report was prepared as an account of work sponsored by an agency of the United States Government. Neither the United States Government nor any agency thereof, nor any of their employees, contractors, subcontractors, or their employees, makes any warranty, express or implied, nor assumes any legal liability or responsibility for any third party's use or the results of such use of any information, apparatus, product or process disclosed in this report, nor represents that its use by such third party would not-infringe privately owned rights. 
Contract No. W-7405-eng-26

Metals and Ceramics Division

THE APPLICATION OF A ONE-DIMENSIONAL POSITION-SENSITIVE DETECTOR TO A KRATKY SMALL-ANGLE X-RAY CAMERA*, $\dagger$ $\equiv$

T. P. Russell and R. S. Stein

Polymer Research Institute

University of Massachusetts Amherst, MA 01003

M. K. Kopp and R. E. Zedler

Instrumentation and Controls Division

and

R. W. Hendricks and J. S. Lin

Metals and Ceramics Division

"Research performed by TPR in partial fulfillment of the requirements for the degree of Doctor of Philosophy from the University of Massachusetts.

$\dagger_{\text {Res }}$

Research sponsured in part by the National Science Foundation under Grant No. DMR 7805925 to the University of Massachusetts and by the Division of Basic Energy Sciences, U.S. Department of Energy, under contract No. W-7405-eng-26 with Union Carbide Corporation.

Date Published: January 1979

OAK RIDGE NATIONAL LABORATORY

Oak Ridge, Tennessee 37830

operated by

UNION CARBIDE CORPORATION

for the

DEPARTMENT OF ENERGY

This report was prepared as an account of work sponsored by the United States Govemment. Neitherithe United States nor the United States Department of Energy, nor any of their employees, nor any of their contractors, subcontractors, or their employees, makes any warranty, express or implied, or assumes any legal liability or responsibility for the accuracy, completeness or usefulness of any information, apparatus, product or process disclosed, or represents that its use would not infringe privately owned rights. 
THIS PAGE

WAS INTENTIONALLY

LEFT BLANK 


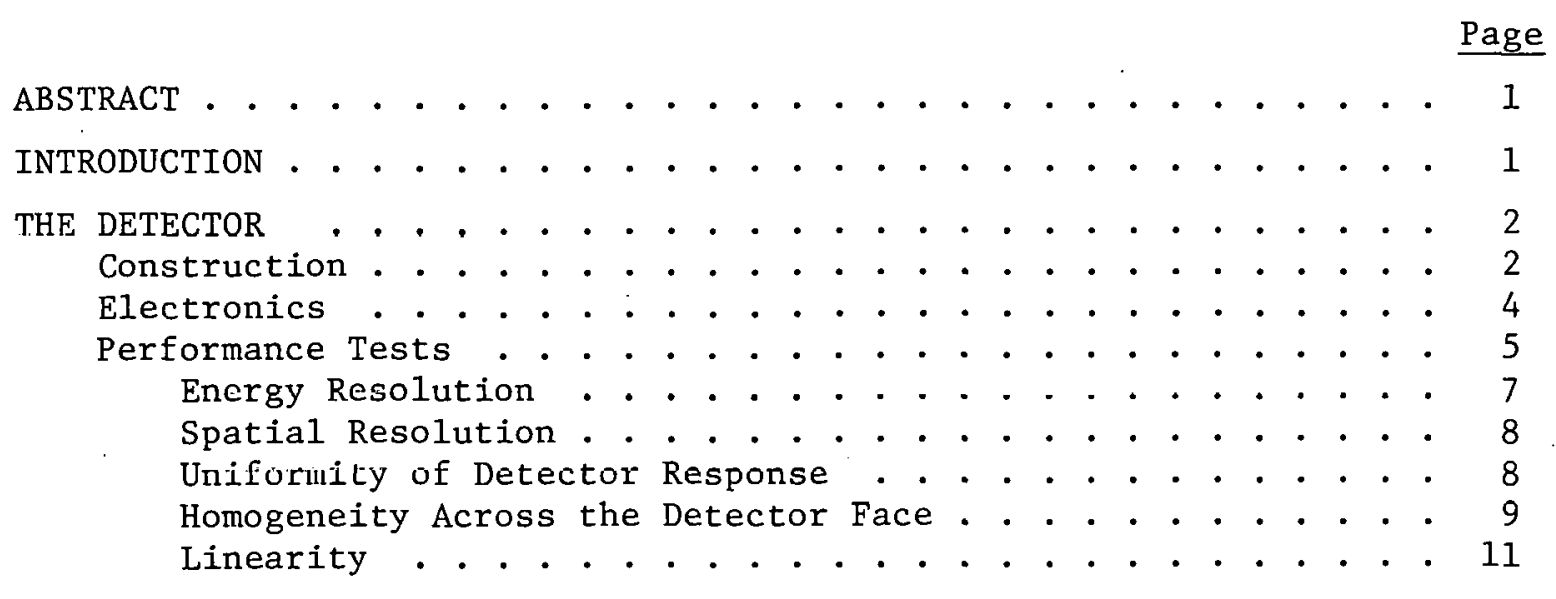

MODIFICATIONS OF THE KRATKY COLLIMATION SYSTEM . . . . . . . . . 13

ALIGNMENT OF THE KRATKY CAMERA WITH A IDPSD . . . . . . . . . . . . 19

Tube Power . . . . . . . . . . . . . . . . . . 19

Initial Rail Alignment . . . . . . . . . . . . . . . 20

Tilt of the Bridge Collimator . . . . . . . . . . . . 22

Vertical Positioning of the Bridge . . . . . . . . . . . 23

Detector Tilt . . . . . . . . . . . . . . . . 25

ALIGNMENT CHECKS . . . . . . . . . . . . . . . . . . . 25

Horizontal Beam Profile . . . . . . . . . . . . . 25

Rocking Curves . . . . . . . . . . . . . . . . . 25

DETERMINATION OF THE ZERO OF ANGLE . . . . . . . . . . . 26

NOISE LEVEL AND PARASITIC SCATTERING . . . . . . . . . . . 28

DEAD-TIME CORRFCTIONS . . . . . . . . . . . . . . . . . . 30

COMPARISON WITH OTHER EQUIPMENT' . . . . . . . . . . . . . . . . . . 32

Comparison with the ORNL 10-m SAXS camera . . . . . . . . . 33

Comparison with a Bonse-Hart System . . . . . . . . . . . 36

Comparison with Uther Kratky Geometries . . . . . . . . . . 38

Polystyrene Comparison . . . . . . . . . . . . 38

Glassy Carbon Comparison . . . . . . . . . . . . . 39

Comments on the Comparisons . . . . . . . . . . . . 40

SPACE CHARGE EFFECTS . . . . . . . . . . . . . . . . . . 40

FILL-GAS EFFECT ....................... . . 45

COMMENTS AND RECOMMENDATIONS . . . . . . . . . . . . . . . 47

Fill Gas... . . . . . . . . . . . . . . . . 47

Detector Wire . . . . . . . . . . . . . . . . 47

Detector Resolution .. . . . . . . . . . . . . . 48

ACKNOWLEDGMENTS . . . . . . . . . . . . . . . . . . . . 49

REFERENCES . . . . . . . . . . . . . . . . . . . . 50

APPENDIX I. Electronfc Determination of Spatial Resolution . . . 53 
THE APPLICATION OF A ONE-DIMENSIONAL POSITION-SENSITIVE DETECTOR TO A KRATKY SMALL-ANGLE X-RAY CAMERA
T. P. Russell, ${ }^{*}$ R. S. Stein, ${ }^{*}$ M. K. Kopp ${ }^{\dagger}$
R. E. Zedler, $†$ R. W. Hendricks, $\neq$ J. S. Lin ${ }^{\dagger}$

ABSTRACT

A conventional Kratky small-angle collimation system has been modified to allow the use of a one-dimensional positionsensitive $\mathrm{x}$-ray detcctor. The detector was designed specifically for use with a long-slit camera and has uniform sensitivity over the entire beam in the slit-length direction. Procedures for alignment of the collimation system are given, dnd a variety of tests of the performance of the system are presented. Among the latter are measurements of electronic noise and parasitic scattering as well as comparisons against samples which were also measured on other cameras. The good agreement of these comparisons demonstrates the success of the use of a positionsensitive detector with the Kratky collimation system.

\section{INTRODUCTION}

An investigation was undertaken to study the small-angle $\mathrm{x}$-ray scattering (SAXS) from amorphous polymers. Such systems are inherently weak, isotropic scatterers. Preliminary experiments on the ORNL 10-m small-angle $x$-ray scattering cameral indicated that the parasitic slitedge background scattering precluded the use of this instrument. However, the advantages of position-sensitive detectors (PSDs) ${ }^{2-4}$ are such that an alternative collimation system which has the necessary low parasitic scattering but which is also amenable to PSDs was sought. The Kratky

$*$

* Polymer Research Institute, University of Massachusetts, Amlerst, MA 01003.

tInstrumentation and Controls Division.

† Metals and Ceramics Division. 
collimation geometry is one of several SAXS geometries noted for both high angular resolution and very low parasitic scattering. 5,6 This report describes our modifications of a commercial Kratky camera for. use with an RC-line encoded one-dimensional position-sensitive detector (1DPSD) and illustrates its performance with scattering patterns from several well-established scattering systems. Recommendations for further modifications are made.

\section{THE DETECTOR}

\section{A. Construction}

With the use of a Kratky geometry, the recorded data must often be desmeared before proper interpretation can be made on an absolute level. As shown by Hendricks ${ }^{7}$ the sensitivity of the detector along the slit-length direction is a function that enters into the desmearing calculations. Therefore, it is desirable to have a position-sensitive detector which has a uniform sensitivity along the slit length, ${ }^{*}$ consequently.simplifying the calculations. This was accomplished with an RCline encoded IDPSD specifically designed for use with a slit geometry. A diagram of the detector is shown in Fig. 1. The design of this detector differs from some of our previous detectors in that the width of the detector window is less than the detector diameter. Iniform $r$-rayr absorption was obtained by using a flat beryllium window and a flat

\footnotetext{
*It is to be noted that a one-dimensional position-sensitive detector mounted with the wire along the $2 \theta$ direction has the slitlength direction normal to the wire.
} 


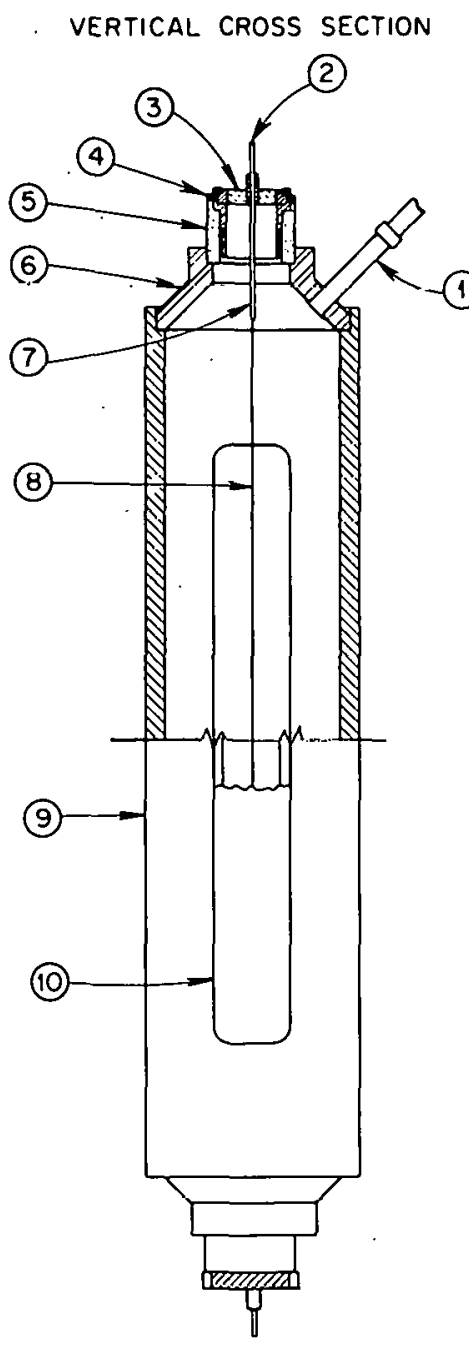

HORIZONTAL CROSS SECTION

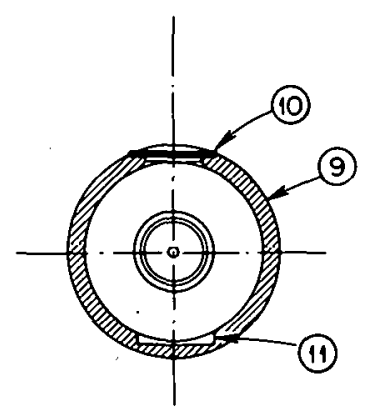

(1) COPPER FILL TUBE

(2) SIGNAL OUTPUT LEAD

(3) GLASS TO METAL INSULATOR

(4) GUARD RING

(5) QUARTZ RING INSULATOR

(6) BRASS CONNECTOR

(7) CAPILLARY TUBE WIRE SUPPORT

(8) GRAPHITE-COATED OUARTZ FIBER $(75 \mu \mathrm{m})$

(9) aluminum cathode

(10) BERYLLIUM WINDOW $(1 \times 10 \times 0.05 \mathrm{~cm})$

(11) MILLED FLAT SURFACE

Fig. 1. One-dimensional position-sensitive detector designed for use with slit geometries.

surface machined opposite the window in the interior surface of the 3.2-cm-ID cylindrical aluminum cathode. These modifications ensured that radiation entering anywhere along the detector window would be absorbed with equal efficiency. Consequently, a uniform sensitivity along the slit length was obtained. ${ }^{*}$.

*An alternate method of achieving the desired uniformity is to use elevated pressures of the fill gas. This is not desirable since additional precautions would have to be taken to contain the gas, higher operating voltages would be needed, and gas purity becomes more critical. 
The components of the detector are shown in Fig. 1. Apart from the modifications described above, they follow standard practice for the construction of proportional counters as described previously. ${ }^{2}$ As can be seen in Fig. 1, the detector is a sealed device. In addition to a $75 \mu \mathrm{m}$ pyrolytic carbon-coated quartz anode, very low capacity guard ring structures were made to help achieve less than $0.5 \mathrm{~mm}$ spatial resolution. Specially shaped truncated conical counter ends were used, and anode capillary tubes were inserted to an experimentally determined length through the guard ring structures to minimize detector end effects and optimize field uniformity for the slit area. Before sealing, the detector components were thoroughly cleaned and the assembly degassed under high vacuum and then filled to 1 atm pressure with a purified mixture of $97 \%$ Xe-3\% cyclopropane. Absorption efficiencies of about $50 \%$ for $17 \mathrm{keV}$ $\mathrm{x}$-rays and $100 \%$ for $8 \mathrm{keV}$ were obtained. The fill tube was crimped closed and sealed with a low-melting solder.

\section{B. Electronics}

RC-1ine position encoding and decoding by pulse-shape-analysis and crossover timing was used. ${ }^{2-4}$ The electronics used for the data acquisition were the same as those used by Schelten and Hendricks, ${ }^{8}$ a diagram of which is shown in Fig. 2. In addition to the position decoding electronics, a beam monitor ${ }^{9}$ was also used. The output signal from its charge integrator was summed with that from the detector and stored in the highest few channels of the multichannel analyzer.

An important feature in the overall design of the detector system is the location of the preamplifiers. To minimize electronic noise these were placed as close as physically possible to the detector so 


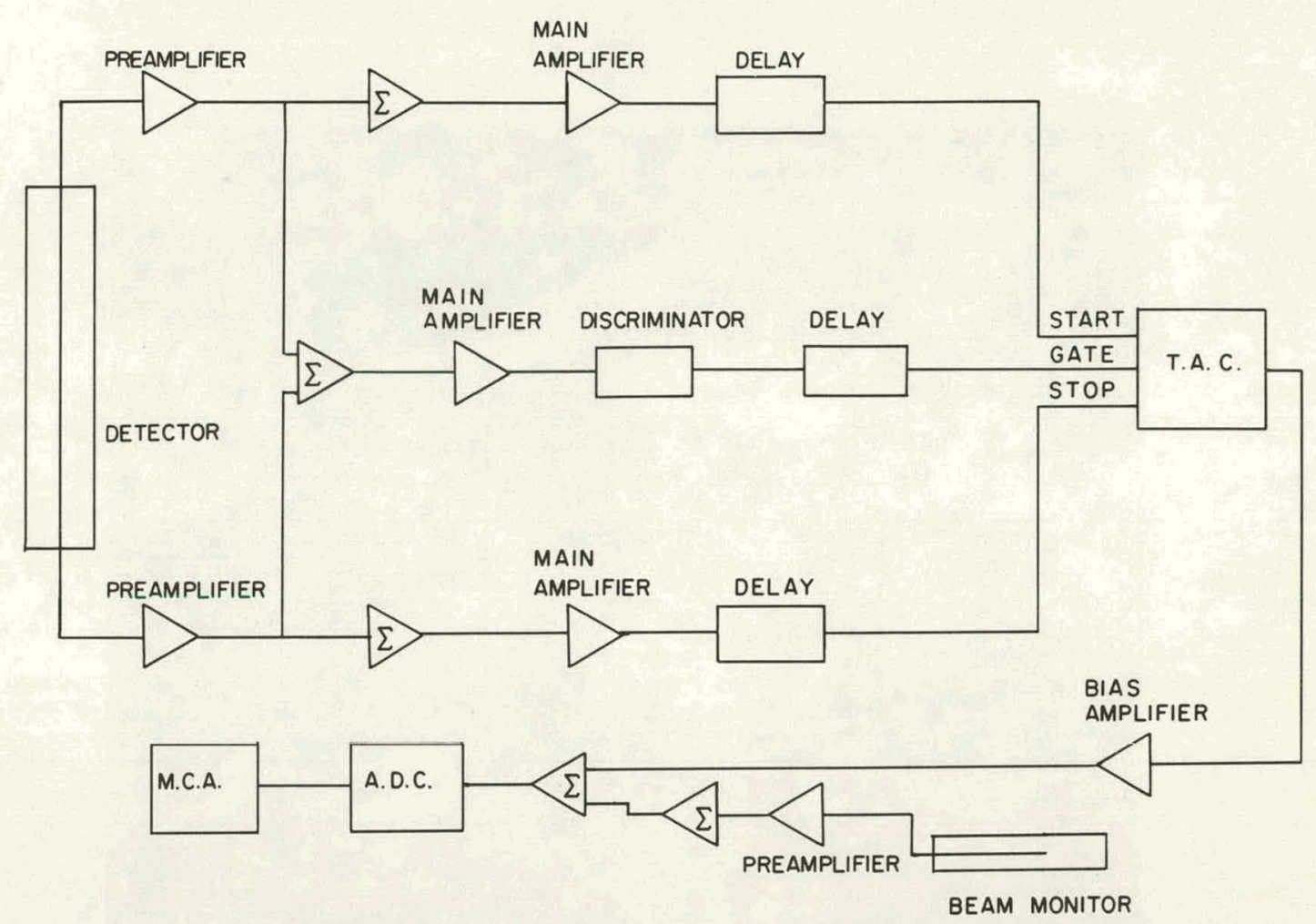

Fig. 2. Analog signal processing electronics for the detector. $\mathrm{ADC}=$ analog to digital converter $\mathrm{MCA}=$ multichannel analyzer; $\mathrm{TAC}$ = time to amplitude converter; $\Sigma$ = summing amplifier.

that the lengths of the output leads from the detector were minimized (Fig. 3). We used hybrid, voltage sensitive preamplifiers with pole-zero cancellation in the feedback circuit ${ }^{10}$ which were designed specifically for position-sensitive detectors. In addition, the preamplifiers were dccoupled to the detector anode. Thus, our detector anode was operated at ground potential and a high negative potential was applied to the shell. The Teflon standoffs for the detector and the safety shield are shown in Fig. 3.

\section{Performance Tests}

The performance of the detector was determined with a $1 \mathrm{mCi}{ }^{55} \mathrm{Fe}$ source ( $1 \mathrm{~cm} \mathrm{dia)} \mathrm{enclosed} \mathrm{in} \mathrm{a} \mathrm{brass} \mathrm{container} \mathrm{with} \mathrm{a} \mathrm{beryllium} \mathrm{window,}$ 


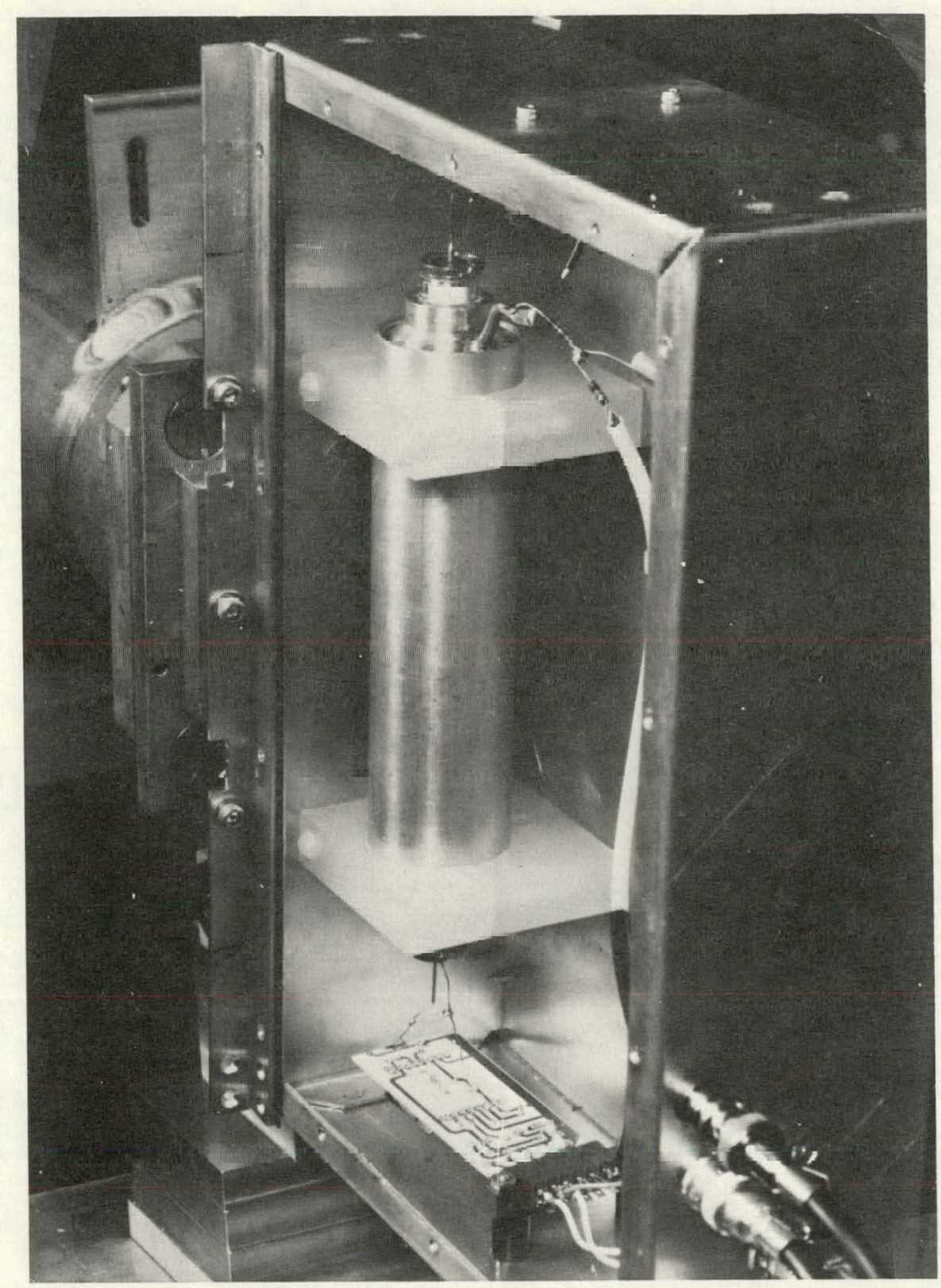

Fig. 3. Position-sensitive detector mounted on Teflon standoffs. One preamplifier is shown at bottom. 
which was capable of operating in vacuum. Unless specified, the detector was operated at $-2600 \mathrm{~V}$.

\section{(a) Energy Resolution}

An energy spectrum was obtained with the ${ }^{55} \mathrm{Fe}$ source illuminating the detector and with the output of the summing amplifiers (Fig. 2) connected directly to the multichannel analyzer. The energy resolution for $\mathrm{MnK}_{\alpha}$ (from ${ }^{55} \mathrm{Fe}$ source) and nickel-filtered copper radiation are shown in Fig. 4. The resolutions are 19 and 23\%, respectively. The resolution was found to be sensitive to the detector bias voltage from -2400 to $-2600 \mathrm{~V}$. A decrease to $29 \%$ resolution was found at $-2600 \mathrm{~V}$.

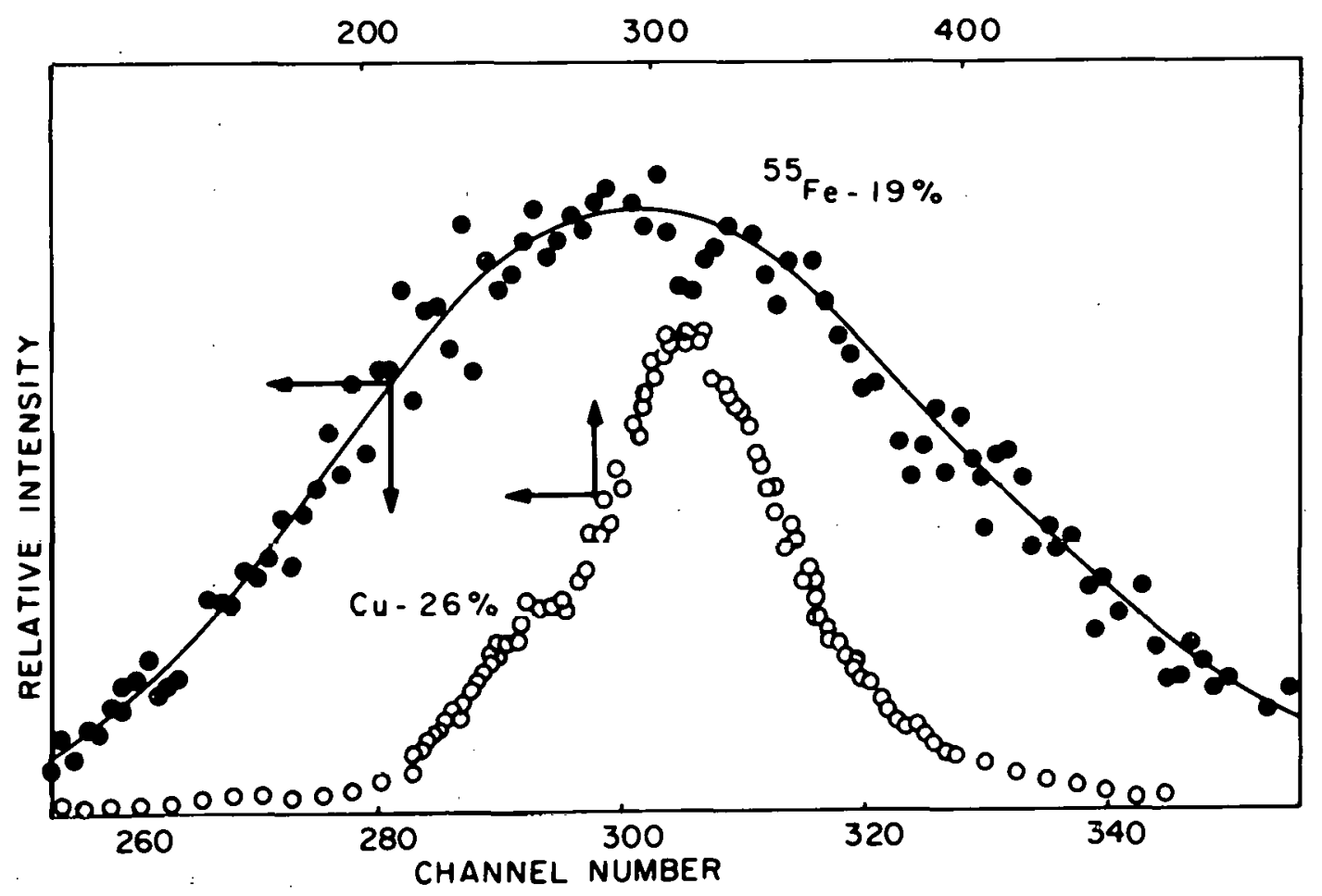

Fig. 4. Detector energy resolution for ${ }^{55} \mathrm{Fe}$ (bottom scale) and nickel-filtered $\mathrm{CuK}_{\alpha}$ (top scale) radiation. 
It is normally expected that the resolution of the higher energy radiation $\left(\mathrm{CuK}_{\alpha}, 8.0 \mathrm{keV}\right)$ would be better than that of the lower energy radiation $\left(\mathrm{MnK}_{\alpha}, 5.9 \mathrm{keV}\right)$. That such is not the case in the results of Fig. 4 can be accounted for because of the considerably broader energy spectrum of the filtered copper radiation, as opposed to the high monochromaticity of the $\mathrm{MnK}_{\alpha}-\mathrm{MnK}_{\beta}$ radiation emitted by ${ }^{55} \mathrm{Fe}$.

\section{(b) Spatial Resolution}

The spatial resolution is the minimum length of the detector wire capable of being distinguished as a unique position. With a ${ }^{55} \mathrm{Fe}$ source $\left(\mathrm{MnK}_{\alpha}\right.$ radiation) in front of a Kratky collimation system, the detector was placed at various distances from the collimator. The width of the beam at the detector was determined geometrically from the width of the entrance slit and the detector to collimator distance. The FWHM of the peak on the MCA was determined as a function of the physical width of the beam. ${ }^{*}$ When decreasing the beam width did not decrease the FWHM of the displayed resolution on the $\mathrm{MCA}$, the resolution limit of the detector was reached. The spatial resolution is $390 \mu \mathrm{m}$ (Fig. 5), in agreement with the electronically determined resolution. (A description of the electronic resolution measurement is given in Appendix I.)

(c) Uniformity of Detector Response

'Ihe $55 \mathrm{Fe}$ source was placed approximately $1.5 \mathrm{~m}$ from the detector in an evacuated chamber ( $5 \times 10^{-6}$ torr) in order to fully illuminate the detector with a uniform intensity. The resulting profile of the

*An alternate approach to evaluate the spatial resolution is to keep the distance between the detector and collimator fixed and vary the width of the beam by adjusting the entrance slit width. 


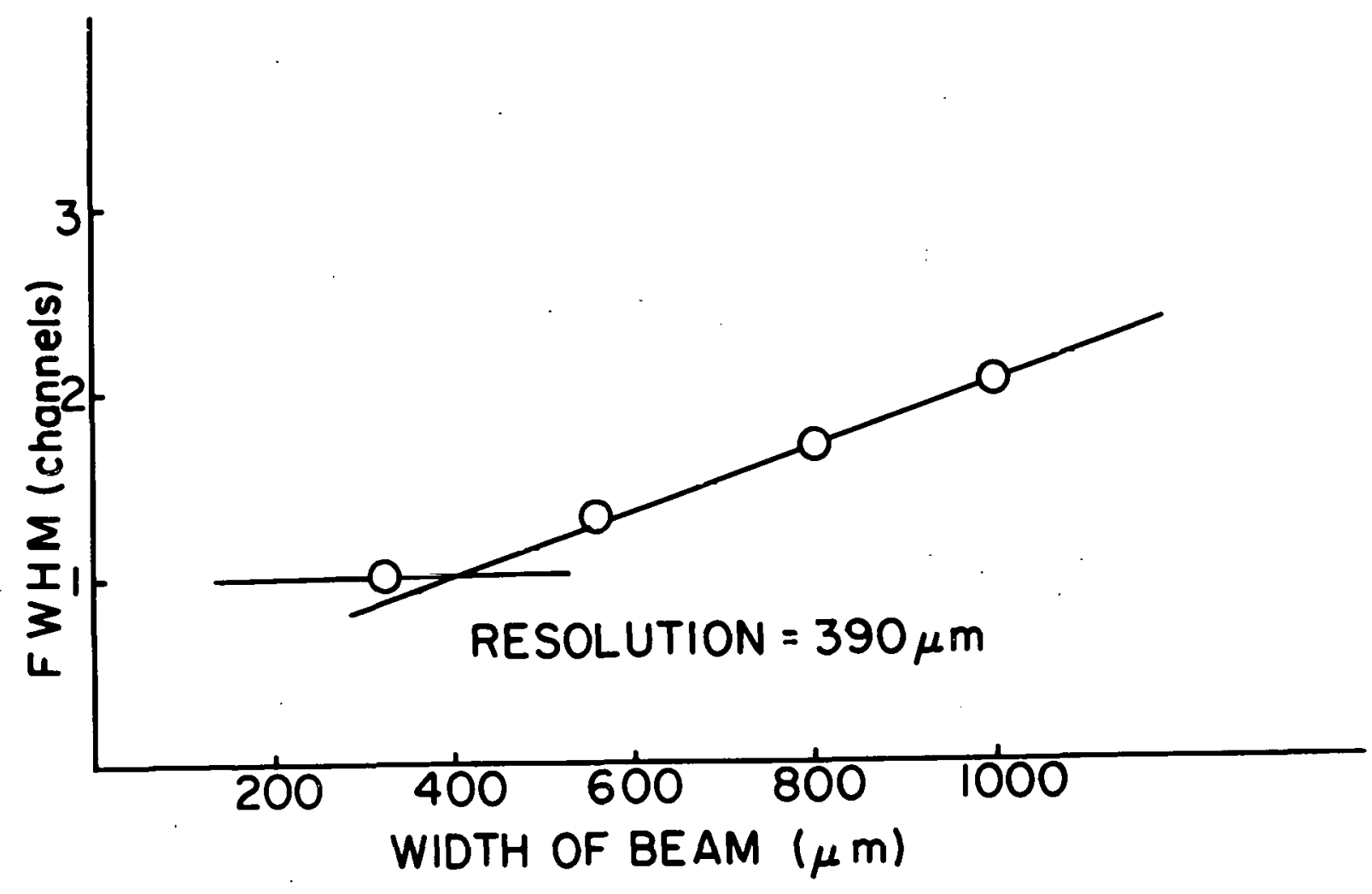

Fig. 5. Spatial resolution of the detector as determined by varying the width of a well-collimated incident beam. A FWHM of 1.0 channel (horizontal line) defines the observable resolution with a given MCA setting. For the data shown here, 512 channels were used.

uniformity or homogeneity of the detector is shown in Fig. 6. All subsequent scattering experiments must be corrected for nonuniform response using these data. We have chosen to scale the data of Fig. 6 to a mean value of unity and then to divide each scattering curve by the resultant normalized sensitivity run channel by channel. The maximum correction factor amounted to $10 \%$.

(d) Homogeneity Across the Detector Face

The detector was designed to yield a uniform collection efficiency across the detector window normal to the wire direction. This was verified by moving a thick narrow slit $(0.5 \times 64 \times 5 \mathrm{~mm}$ thick) oriented parallet to the detector wire across the face of the detector. Care was taken 


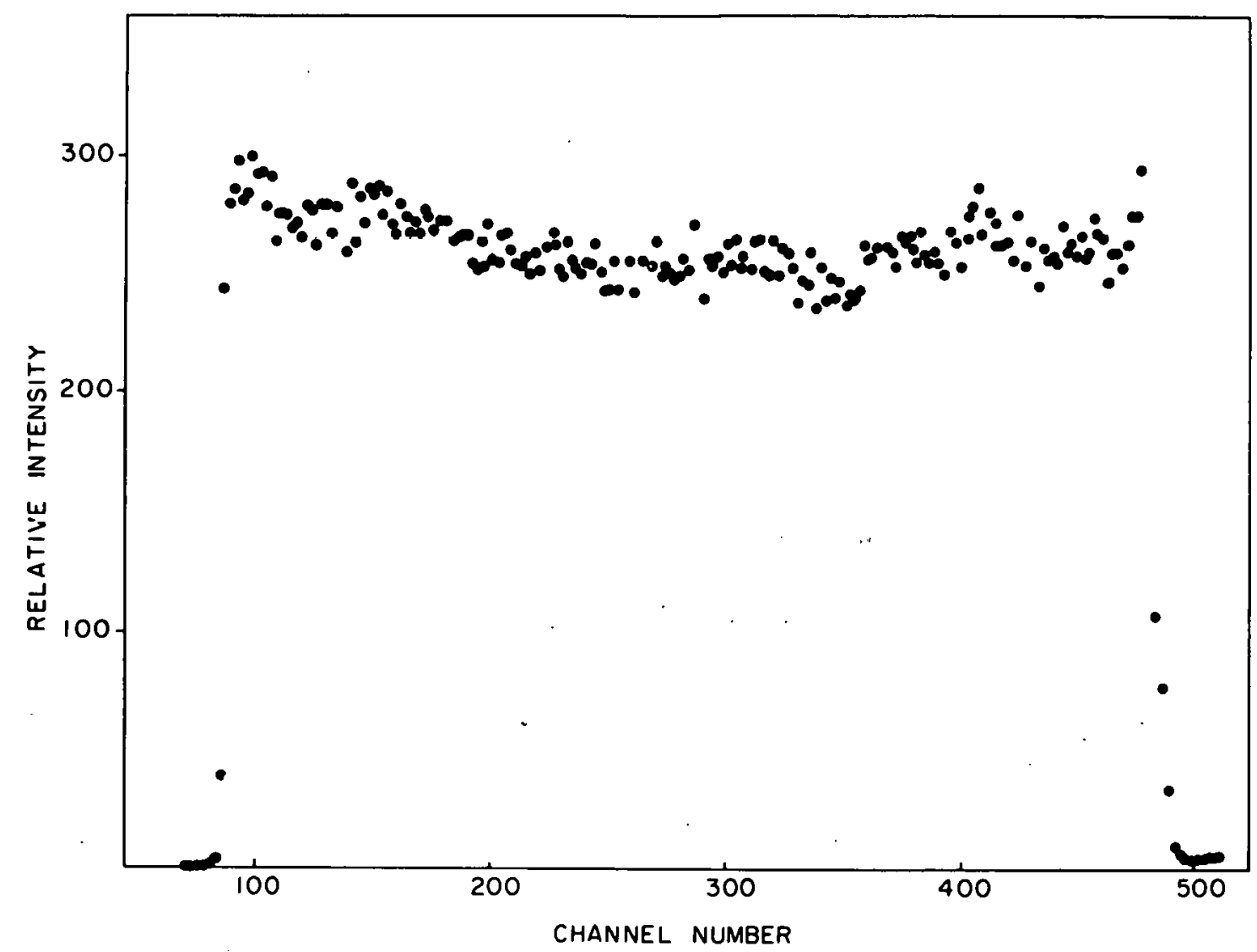

Fig. 6. Detector homogeneity as determined by measuring a ${ }^{55} \mathrm{Fe}$ source at $1.5 \mathrm{~m}$.

to minimize the divergence of the beam. Figure 7 displays a superposition of several runs at various points across the window of the detector. As can be seen, the runs are indistinguishable. Therefore, the desired uniform collection efficiency was achieved.

The reason that Figs. 6 and 7 are not of identical shape is a result of the position of the ${ }^{55} \mathrm{Fe}$ source in each test. For the latter test the source-to-detector distance was much smaller in order to increase the intensity. However, the divergence in the direction normal to the wire was minimized by using a thick slit $(5 \mathrm{~mm})$. 


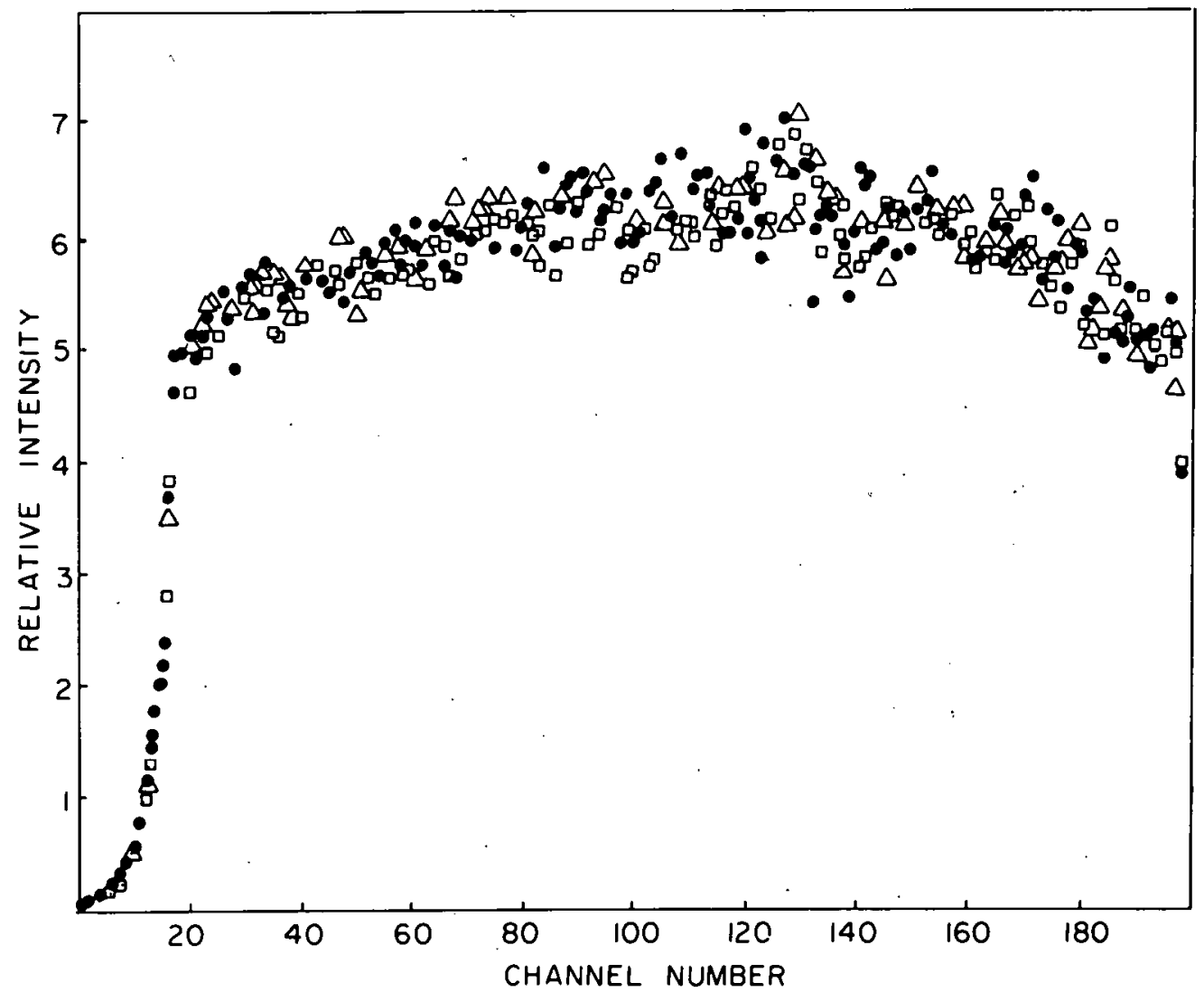

Fig. 7. Homogeneity across detector window as determined by moving a long, narrow $(64 \times 0.5 \mathrm{~mm})$ slit across the detector face with the long dimension parallel to the detector wire.

(e) Linearity

The linearity of the detector was determined in a manner identical to that of Schelten and Hendricks. ${ }^{8}$ With the source approximately $1.5 \mathrm{~m}$ from the detector, a lead mask containing sixteen 1-mm slots, separated by $6.1 \mathrm{~mm}$ from slot center to slot center, was placed immediately before the detector. The profile resulting from this is shown in Fig. 8. The centroids of the maxima were determined as a function of channel number and are plotted versus their real-space separation in Fig. 9. These data were fitted with various polynomials to calibrate 


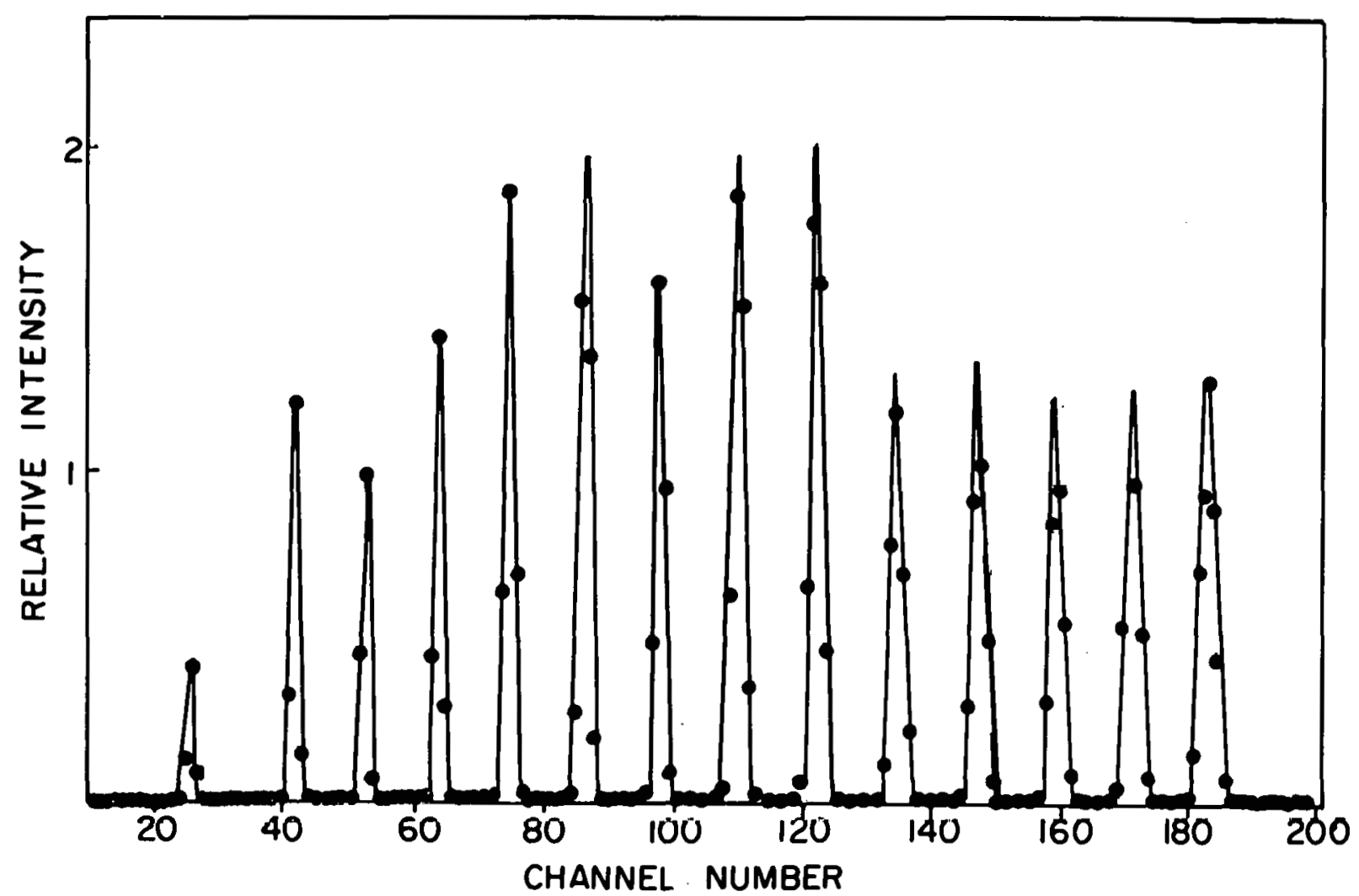

Fig. 8. Linearity test as determined by recording a ${ }^{55} \mathrm{Fe}$ spectrum with a mask consisting of 15 narrow (1 mm) slits normal to the detector length in front of the detector.

the MCA with real space.* The best fit was found to be a quadratic polynomial of the form

$$
Y=-12.91+0.45 \dot{X}+6.80 \times 10^{-4} \mathrm{X}^{2}-2.36 \times 10^{-6} \mathrm{X}^{3}
$$

where $\mathrm{Y}$ represents the distance in real space from the origin corresponding to a channel $\mathrm{x}$. These results demonstrate that the detector was reasonably linear over its useful length.

* The position of the origin on the MCA is arbitrary. During this experiment zero was selected as the position of the first maximum, occurring at channel number 26 . 


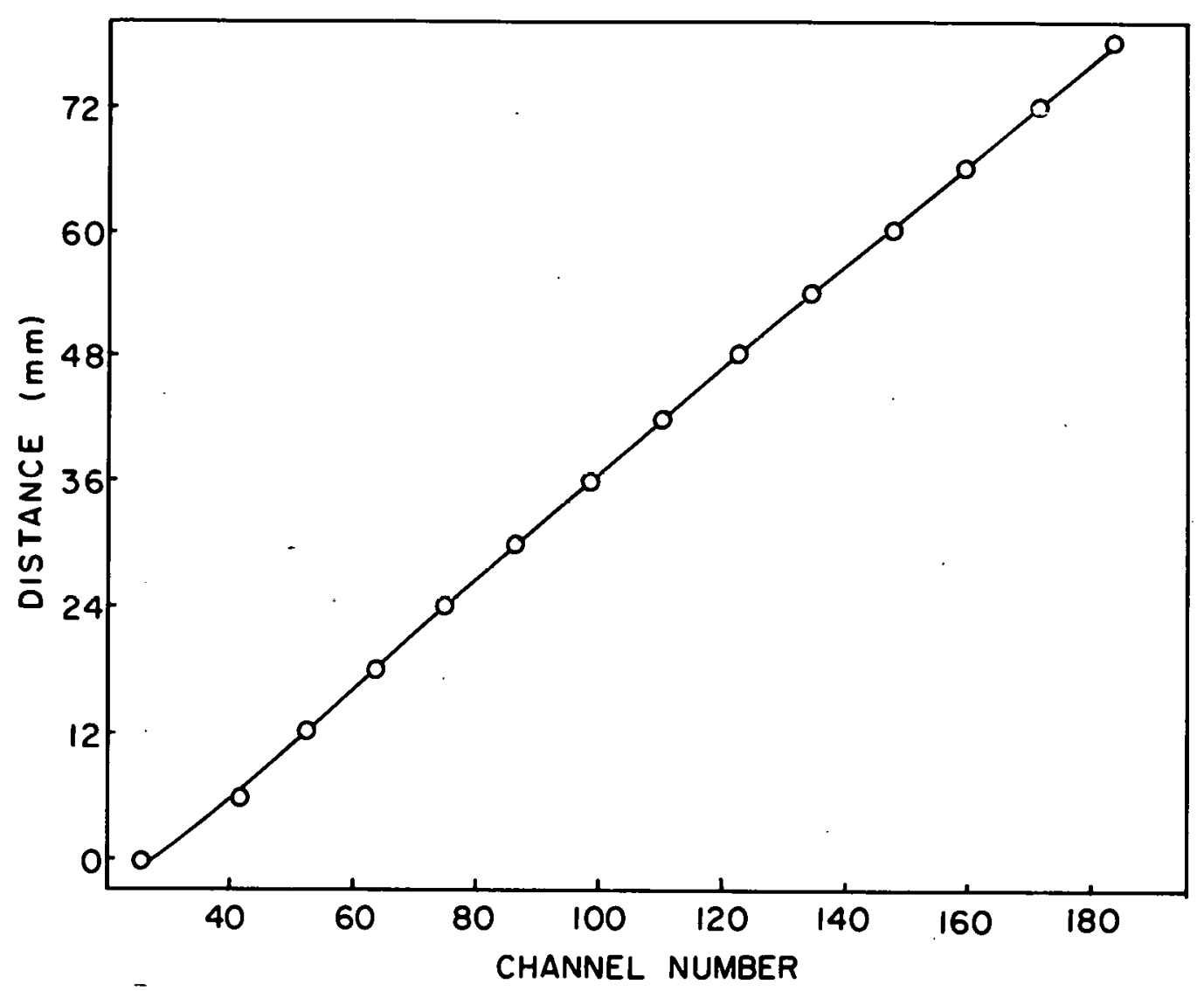

Fig. 9. Detector 1inearity.

III. MODIFICATIONS OF THE KRATKY COLLIMATION SYSTEM

The essential feature of the Kratky collimation system is the use of a U-block and bridge. ${ }^{5,6}$ These components ultimately define the main beam profile, the amount of parasitic scattering, and the angular resolution. Although not so common these days as the camera with a moveable tank which is equipped with an adjustable narrow slit for stepscanning with electronic detectors, Kratky cameras have also been equipped with receiving slits some $10 \times 50 \mathrm{~mm}$ for use with film cassettes. Since, like film, the IDPSD acquires the entire scattering profile simultaneously, the vacuum tank for a system utilizing the PSD must be geometrically similar to the film camera. Therefore, the 
commercially available camera (schematically shown in Fig. 10) had to be modified. The extent of modification depends upon the spatial resolution of the detector and the desired angular resolution. In this present case, a system was desired which had an angular resolution of $0.2 \mathrm{mradian} / \mathrm{channel}$. With the $400 \mu \mathrm{m}$ spatial resolution of the detector, this required a flight path (sample-to-detector distance) of $1.6 \mathrm{~m}$. The collimation system parameters for the new camera are given in Table 1 . In the modified camera (Fig. 11), the normal flight path (approximately 200-215 mm) was replaced by a length of aluminum tubing in which the diameter was doubled partway along its length. The first section was $36.5 \mathrm{~cm}$ long (8.9-cm inner diameter) and the second section was $93.4 \mathrm{~cm}$ long (19.1-cm inner diameter). The large diameter section was required to avoid intercepting the main beam by the inner walls of the tubing.* Both sections were lined with $0.04-\mathrm{cm}$-thick lead shielding to eliminate any small reflections or diffraction effects from the aluminum walls. The front section of the flight path was mounted onto a flange that was compatible with the initial section of the flight path of the commercially available camera. Therefore, the tilting mechanism of the original camera could be retained for alignment purposes. An aluminum flange, in which a $1 \times 18 \mathrm{~cm}$ vertical slot was cut, was mounted with an 0-ring on the rear of the new flight path. The slot was sealed with a sheet of $0.05-\mathrm{cm}$-thick beryllium on the outside surface of the flange as shown in Fig. 12(a). This was epoxied in place so that it was below the surface level of the external face. For alignment purposes the rear flange

*An earlier design, in which only 8.9-cm-dia tubing was used, had a parasitic scattering some 1000 times above that of the present design. This was determined to be scattering and fluorescence caused when the outer edges of the diverging main beam touched the tube walls. 


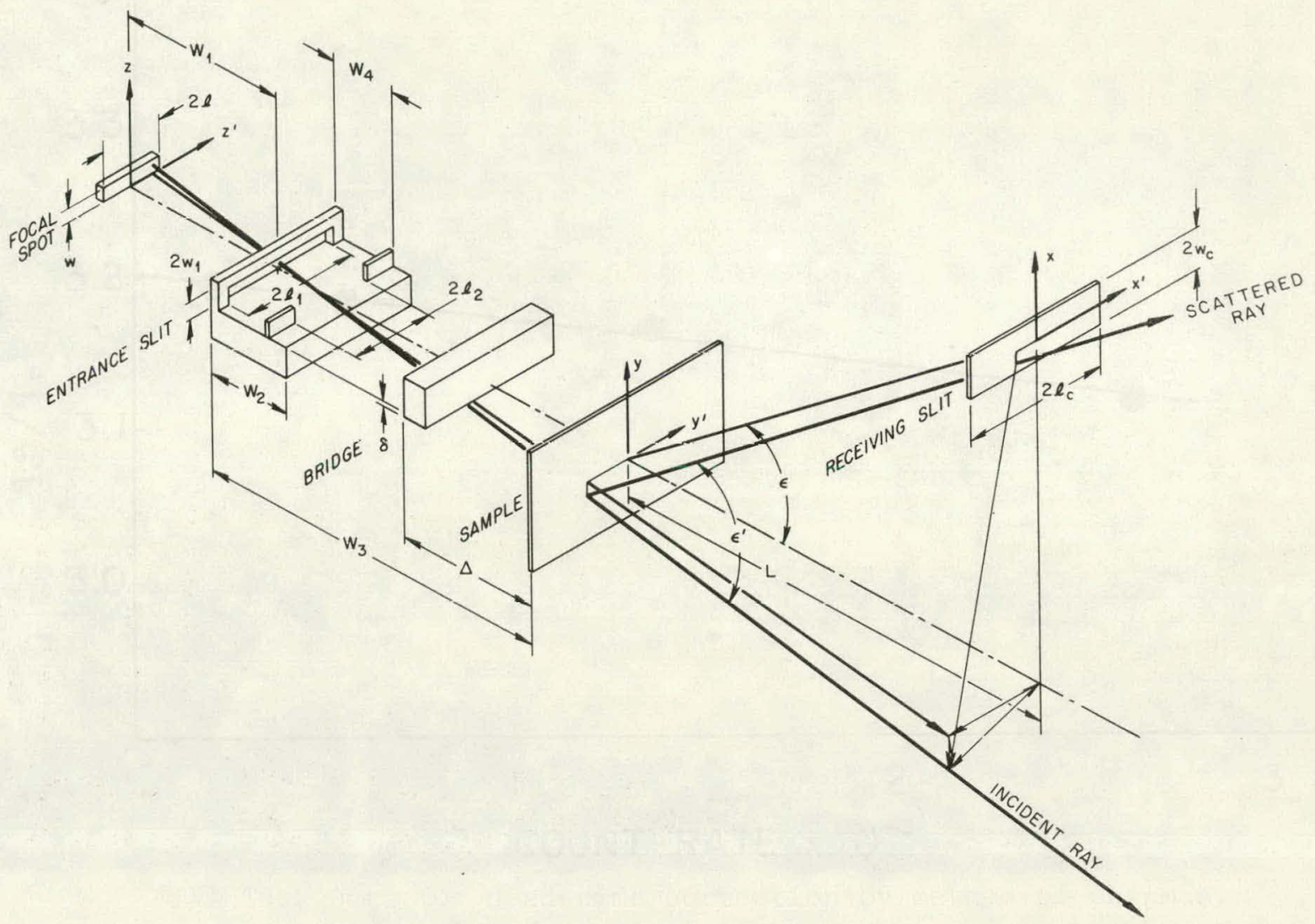

Fig. 10. Schematic of normal Kratky camera.

Table 1. Kratky Camera Collimation System Parameters*

\begin{tabular}{|c|c|c|c|}
\hline \multicolumn{2}{|c|}{ Slit Width } & \multicolumn{2}{|c|}{ Slit Length } \\
\hline Parameter & $\begin{array}{c}\text { Value } \\
(\mathrm{mm})\end{array}$ & Parameter & $\begin{array}{r}\text { Value } \\
(\mathrm{mm})\end{array}$ \\
\hline $2 \mathrm{w}_{1}$ & 0.065 & $2 \ell$ & 7.0 \\
\hline$\delta$ & 0.0 & $2 \ell_{1}$ & $\infty$ \\
\hline $2 w_{c}$ & 0.450 & $2 l_{2}$ & 14.0 \\
\hline $\mathrm{L}_{0}$ & 298.0 & $2 e^{2}$ & 10.0 \\
\hline $\mathrm{W}_{1}$ & 103.0 & $W_{4} \mathrm{C}$ & 125.0 \\
\hline$W_{2}$ & 60.0 & $\mathrm{~L}$ & $1543.6^{\dagger}$ \\
\hline $\mathrm{W}_{3}$ & 195.0 & & \\
\hline$\triangle$ & 70.0 & & \\
\hline L & $1551.0^{\top}$ & & \\
\hline
\end{tabular}

*See Fig. 10 for definition of variables.

$t_{\text {The value of }} \mathrm{L}$ in the slit-width direction is from the sample to the wire, while in the slit-length direction it is from the sample to the machined edge of the detector window. 

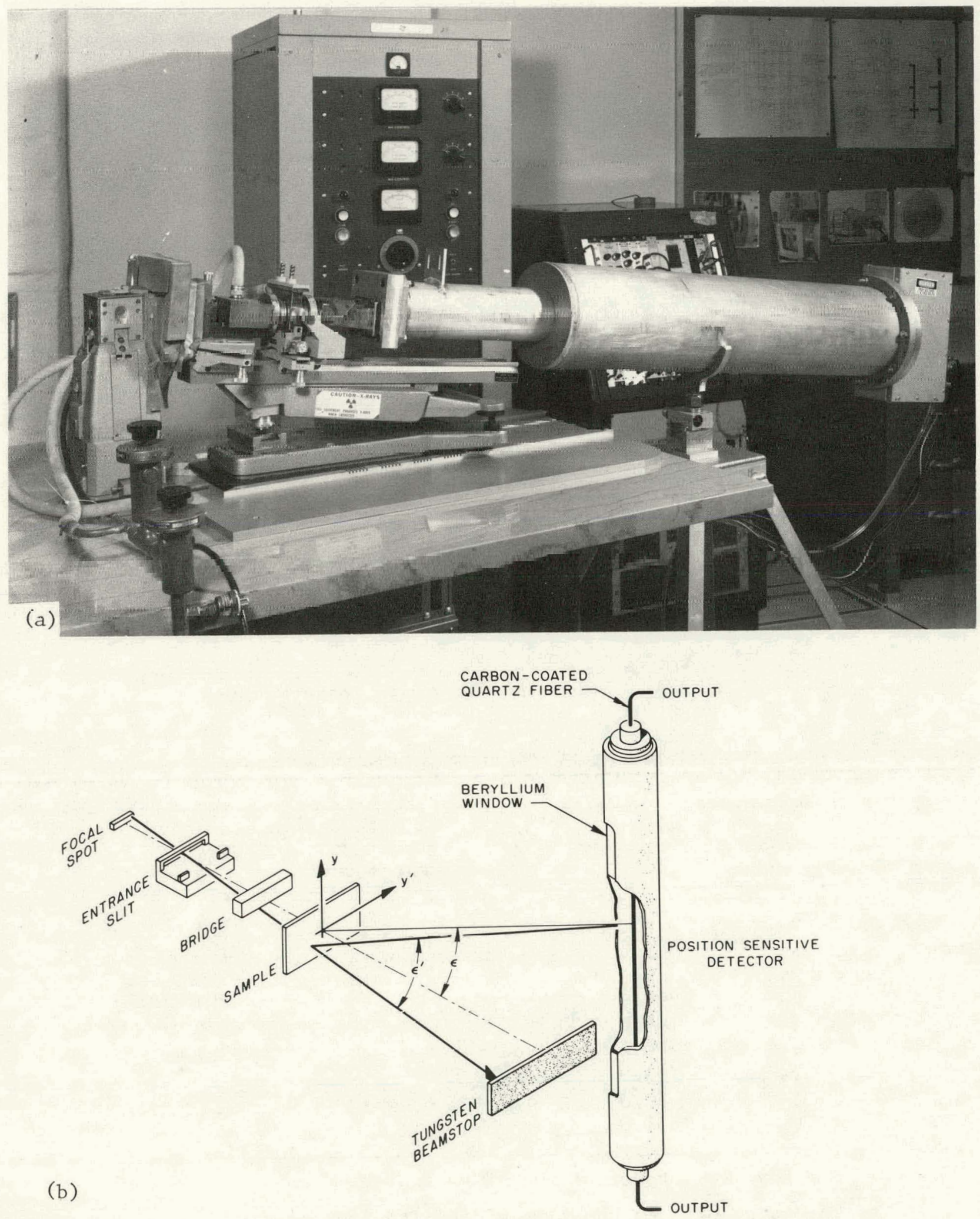

Fig. 11(a) Photograph of apparatus; (b) schematic of system with IDPSD. 

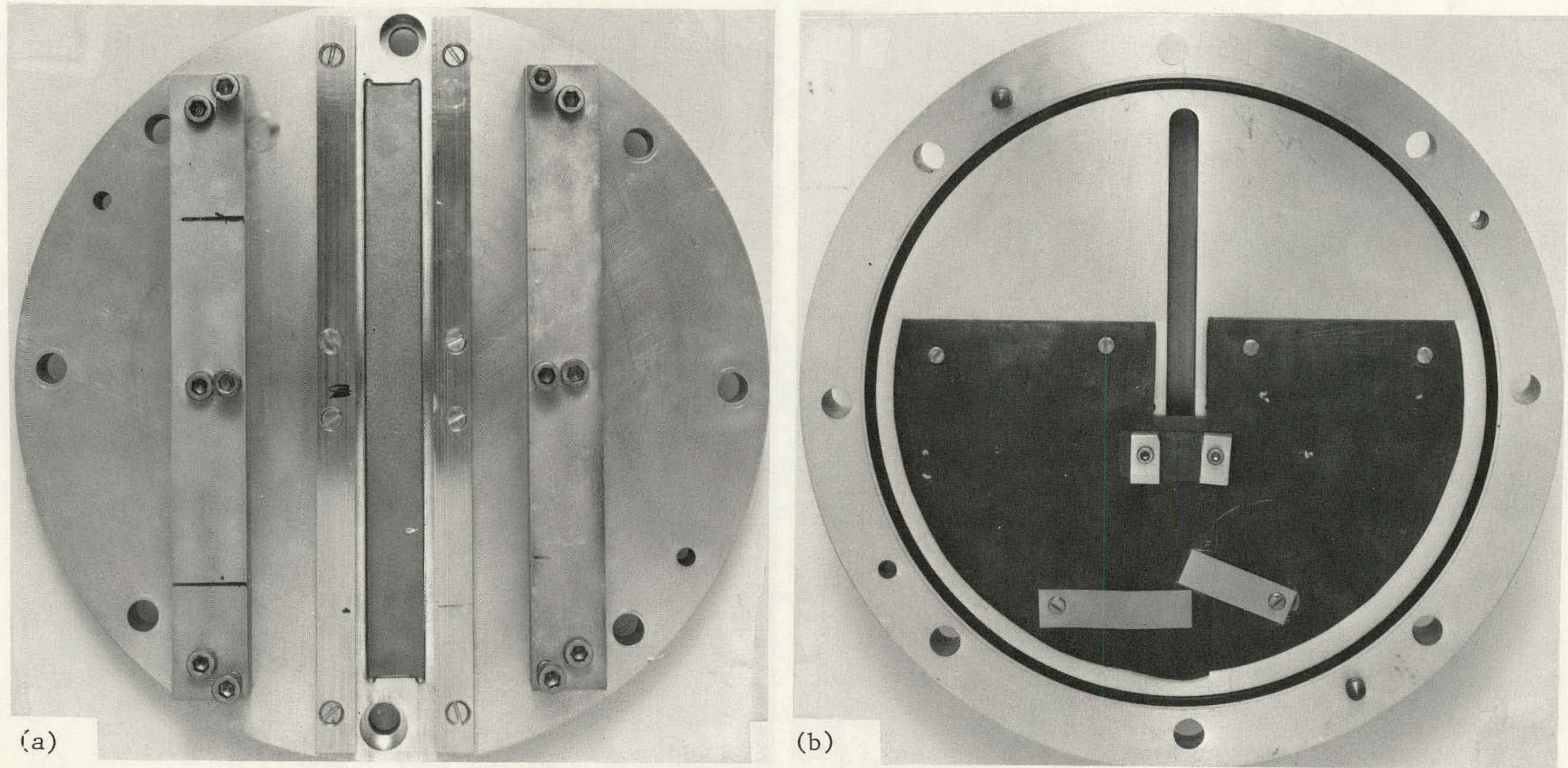

Fig. 12. Views of the rear flange. (a) Exterior, showing beryllium window and ways for mounting detector, and (b) interior, showing spring clamps for holding polished tungsten edge and alignment pins to allow precise $90^{\circ}$ rotation of the detector. 
contained two pairs of pins perpendicular to each other so that the slot could be oriented either parallel or penpendicular to the incident beam. A tungsten beam stop (polished to within $4 \times 10^{-5} \mathrm{~cm}$ tolerance limits) was held across this slot by an adjustable mounting on the internal* face of the flange as shown in Fig. 12(b). Careful machining ensured that the beam stop was mounted perpendicular to the slot. The internal face was covered with $0.04 \mathrm{~cm}$ lead shielding to prevent any back reflections of the incident beam. Two slides for adjusting the position of the detector along the slot and for mounting various test equipment were placed on the external face of the flange parallel to the slot.

In addition to these modifications the camera was equipped with vacuum bellows from the bridge collimator to the sample chamber to the beam flight path, an automated balanced filter assembly and an incident beam monitor. All of these have been described elsewhere. $9,11,12$

Combining these modifications with the 1DPSD permitted the measurement of scattering patterns down to 0.7 mradian of angle with a minimum amount of parasitic and air scattering. One point that should be emphasized is that there is a significant loss in recorded intensity because of the extended flight path. Since the active area of the detector in the slit length direction was limited to $1 \mathrm{~cm}$, due to the divergence of the beam in this direction the intensity loss at any scattering angle $2 \theta$ is $1550 / 220=\mathrm{X} 7$.

* It is essential to mount the tungsten beam stop on the internal face of the flange so that the indicent $x$-ray beam does not impinge upon the beryllium window. Strong diffraction maxima can be seen if the beam stop is placed after the beryllium window. ${ }^{8}$ 


\section{ALIGNMENT OF THE KRATKY CAMERA WITH A 1DPSD}

The alignment procedure described in this report is that which was developed for the present camera geometry. The nomenclature used follows that of Anderegg et al. 13 The extended flight path placed severe limitations on using the normal procedures of alignment since it had to remain attached to the camera during the fine adjustments. It was found that if the camera was finely adjusted without the flight path using the normal alignment procedures then when the flight path was mounted the alignment was disturbed simply due to its size and mass. If a detector of higher spatial resolution were used, then the flight path could be shortened considerably, making normal alignment methods more feasible.

\section{A. Tube Power}

During the course of alignment the special Siemens Kratky tube $(2.7 \times 7 \mathrm{~mm}$ focal sput) wás operated at $30 \mathrm{kV}$ and $1 \mathrm{~mA}$. The reasons for such low power settings are twofold. First of all, the low power avoids the use of thick nickel attenuators to reduce the power of the beam, thus avoiding the increasing amount of hard radiation in the energy spectrum. Secondly, the lower power reduces the chance of destroying the carbon coating on the quartz wire either by evaporation of the coating or by decomposition of the quenching gas with subsequent deposition on the wire. Both will seriously affect the response of the detector.

One problem that can arise from the use of lower power settings during the alignment stage is that ultimately the power must be increased for experimental use. This can easily cause a heating of the focal spot 
and, consequently, the rocking curve can be disturbed. This can lead to either a reduction or an increase in the resolution by changing the first moment of the incident beam profile. Neither of these can be tolerated for precise work. Therefore, an independent investigation was conducted using a normal step-scanning Kratky apparatus where the rocking curve was determined as a function of power setting. Provided sufficient time was allowed for the focal spot to equilibrate, the rocking curve remained constant with the center of gravity (i.e:, the first moment) changing by at most $2.0 \times 10^{-2}$ mradian.

\section{B. Initial Rail Alignment}

A bridge system with the desired entrance slit width was placed at the front of the rail and a calibrated fluorescent screen (supplied with the camera) was mounted approximately $10 \mathrm{~cm}$ behind the bridge. Using $v_{1}$ the vertical position of the rail was roughly set so that the beam was visible on the fluorescent screen. If the beam was not perpendicular to the marks on the screen, then the bridge tilting micrometer, $\mathrm{T}_{1}$, was adjusted to compensate for this. With the beam perpendicular to the markings and roughly maximized, the symmetry of the beam about the center of the rail was determined. If the symmetry was poor $\mathrm{H}_{1}$ and $\mathrm{H}_{2}$ were adjusted until satisfactory symmetry was obtained.

The fluorescent screen was moved further back on the rail (approximately $40 \mathrm{~cm}$ from the bridge) and the symmetry was checked. Again, if it was not satisfactory, $\mathrm{H}_{1}$ and $\mathrm{H}_{2}$ were adjusted accordingly. The screen was then returned to the initial position and symmetry was rechecked. Measurements of both settings were repeated until symmetry was obtained at both positions without moving the rail. 
More quantitative adjustments can be made at this point with a non-position-sensitive detector mounted in the horizontal scanning device (supplied with the camera). With the detector equipped with a pinhole, the vertical position of the detector was adjusted to optimize the count rate. Horizontal scans were then made at 10 and $40 \mathrm{~cm}$ from the bridge system. These scans provided quantitative information regarding the symmetry, homogeneity and width of the beam. One of these scans is shown in Fig. 13. Adjustments were then made on $\mathrm{T}_{1}, \mathrm{H}_{1}$ and $\mathrm{H}_{2}$ so that the resulting profile had the required trapezoidal shape.

The width of the beam can be quantitatively determined at various positions along the rail and can be compared to the geometrically calculated width. Similarly, once the beam width is known at various positions on the rail, the focal spot length can be calculated and compared

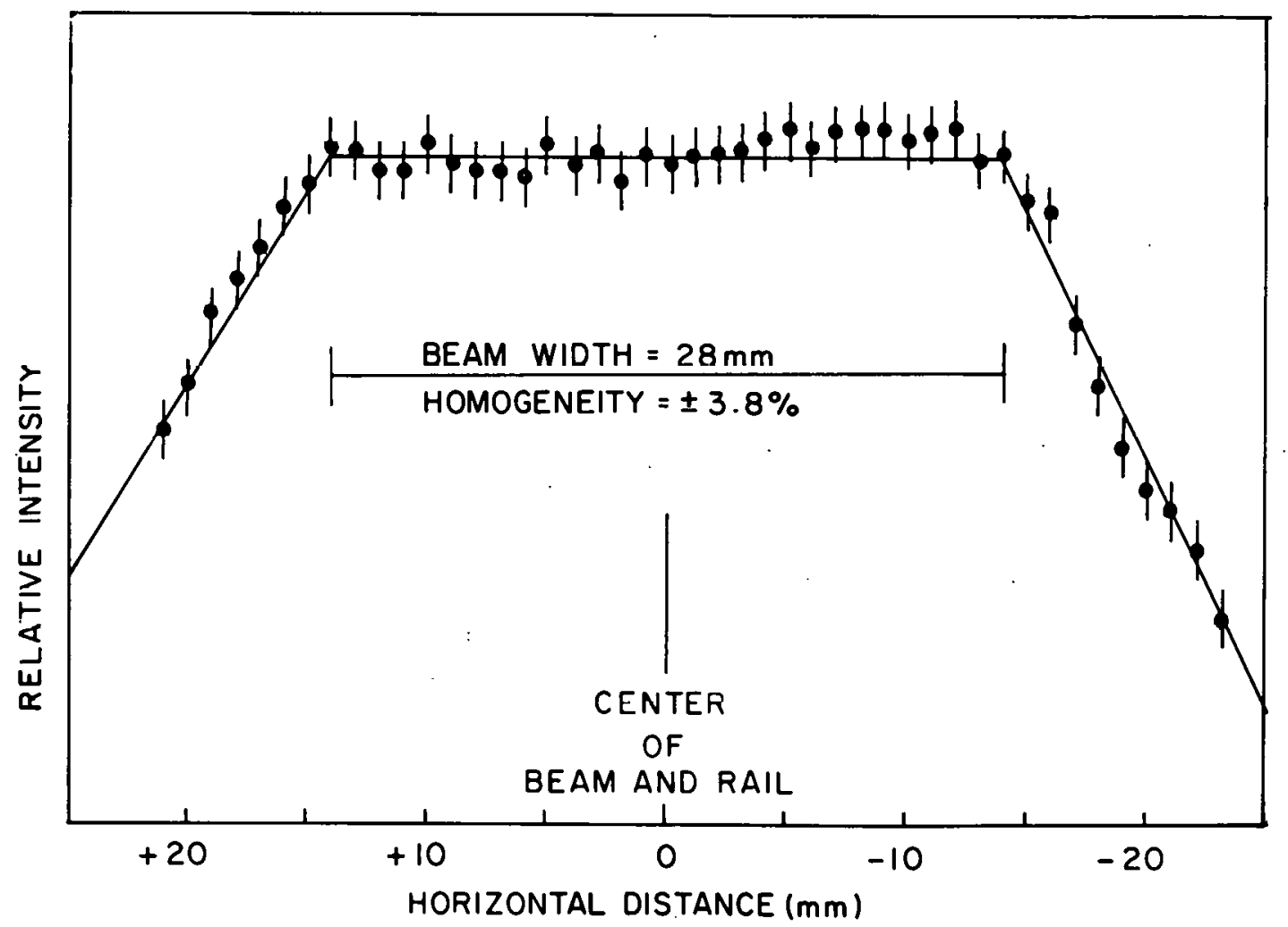

Fig. 13. Horizontal beam scans. 
to the known $(7 \mathrm{~mm})$ length. If either method produces erroncous results, then the focal spot is not parallel to the collimation system. Once satisfactory agreement has been found by rotation of the $x$-ray tube and movements of $\mathrm{H}_{1}$ and $\mathrm{H}_{2}$, the sample chamber can be mounted on the rail so that it does not interfere with the main beam.

With the beam stop removed from the rear flange, the vacuum flight path was mounted and the system was evacuated to $\sim 5 \times 10^{-6}$ torr. The detector was attached to the rear flange perpendicular to the incident beam. By adjustment of the micrometer $D_{4}$ now mounted on an external stand with 1-cm-thick Al plates as adjustable shims for coarse adjustment, the beam, attenuated with copper foils, was brought to midrange on the MCA. The detector was now in a position to receive any radiation coming through the bridge system.

\section{Tilt of the Bridge Collimator}

The bridge collimation system.was set parallel to the focal spot by determining the tilt at which a minimum traverse distance through the beam using $V_{1}$ was obtained.* For a given tilt setting the focal spot was scanned using $V_{l}$ noting the settings of $v_{l}$ corresponding to an arbitrary count rate on either side of the focal spot. The difference between these readings corresponds to an effective focal spot width. This difference was plotted as a function of the tilt of the sollimatnr, and the minimum determined the tilt at which the bridge collimation system was parallel to the focal spot. These data, along with the tilt

\section{$*$}

This procedure differs from that of Anderegg et al.1.3 who used a narrow slit positioned at various distances along the focal spot. Because of inhomogeneities of the focal spot, it was concluded that the present procedure gives a better average alignment. 
selected, are given in Fig. 14. (Note: The special locking bolt on the tilt mecharism described by Hendricks ${ }^{1}$ must be tightened to a constant torque at each different tilt setting to ensure reproducibility.)

\section{Vertical Positioning of the Bridge}

The focal spot was scanned vertically using $v_{1}$ as shown in Fig. 15. An insensitive portion of the profile was selected for positioning $v_{1}$. A similar scan was performed using $v_{2}$ with $v_{1}$ locked in place. Again, an insensitive region was selected to position $v_{2}$. Scans of the focal spot were repeated until the readings of $v_{1}$ and $v_{2}$ did not change. A convenient check on the procedure verifying that the rail is at a $6^{\circ}$ take-off angle is to calculate the effective width of the focal

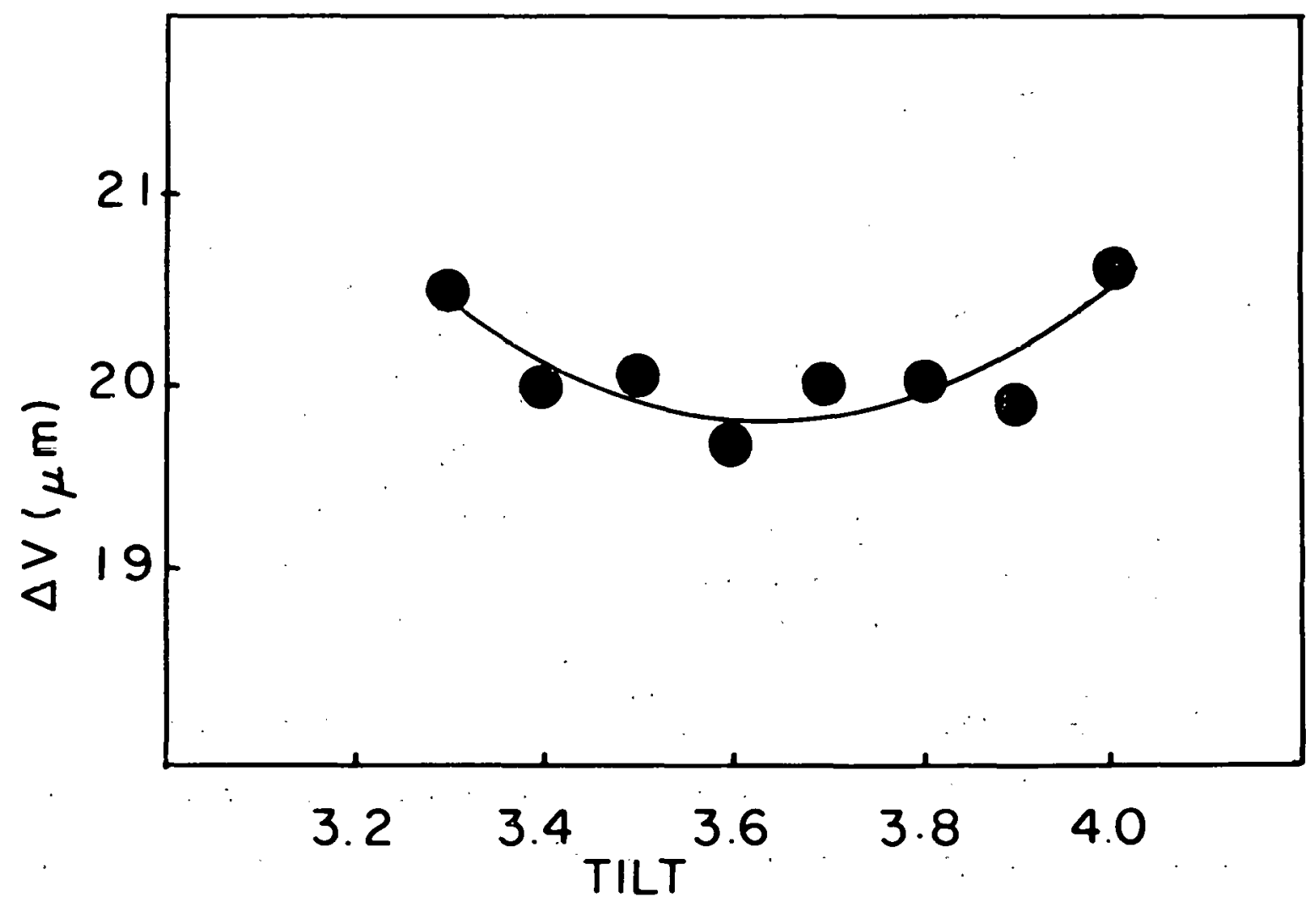

Fig. 14. Tilt of collimator experiment. The minumum is at a tilt of 3.65 units. 


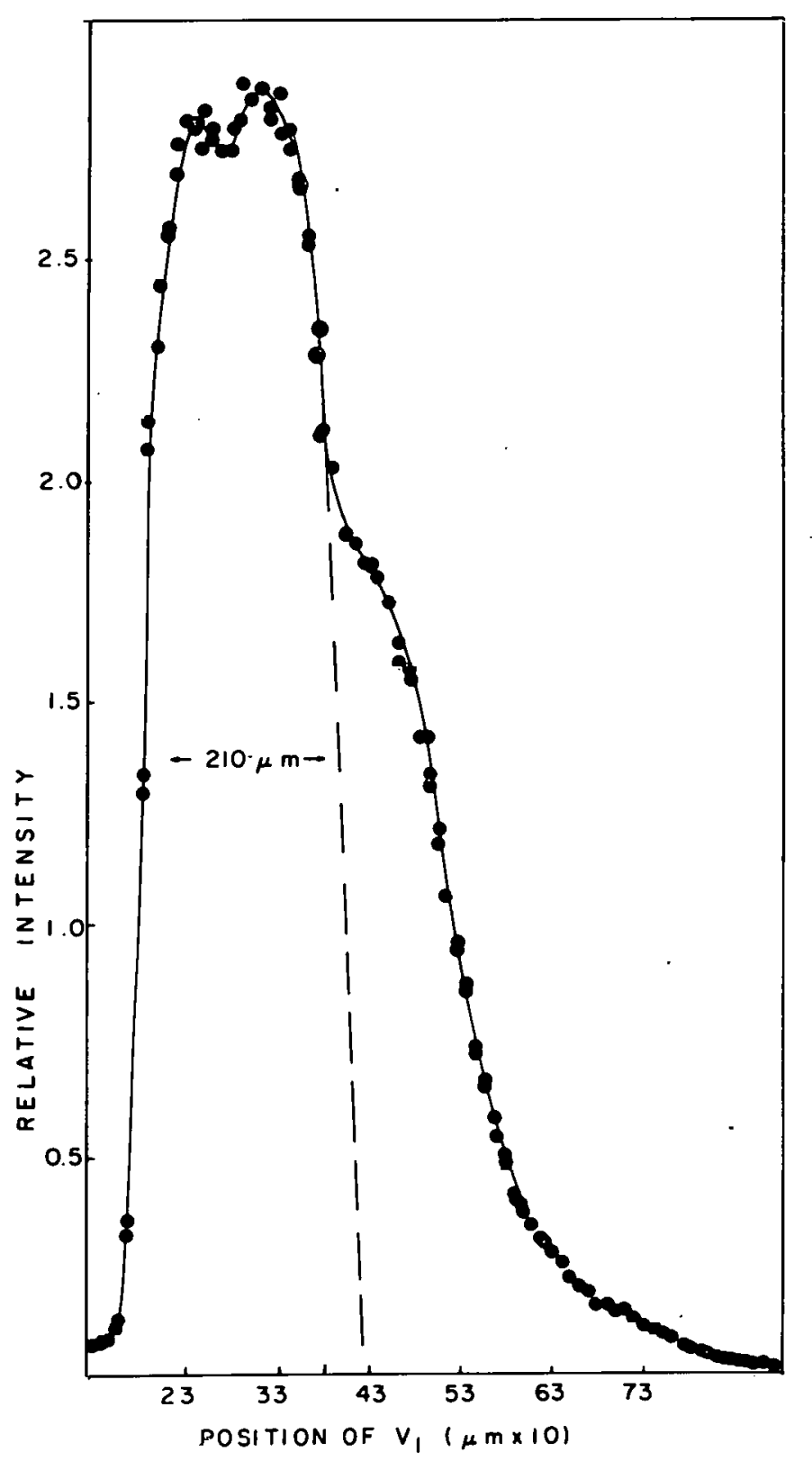

Fig. 15. Vertical profile of beam.

spot and compare this to the actual size of the focal spot. For this experiment the effective size of the focal spot was $0.0205 \mathrm{~cm}$ which corresponds to a $5.95^{\circ}$ take-off angle. 


\section{E. Detector Tilt}

The detector receiving slit and tungsten edge were set perpendicular to the incident beam by determining the total number of background counts versus the tilt of the vacuum chamber. When the edge is perpendicular to the beam, then the total counts will be minimized. Alternatively, the detector can be rotated $90^{\circ}$ and the homogeneity of the beam can be determined and $\mathrm{T}_{2}$ can be rotated until a homogeneous profile is found. Both methods were used with good agreement.

\section{ALIGNMENT CHECKS}

\section{A. Horizontal Beam Profile}

With an aligned Kratky camera the horizontal profile of the beam should have a trapezoidal shape. The length of both the homogeneous section and the penumbra can be geometrically determined and compared to that obtained experimentally. This was done as is shown in Fig. 16. Due to the physical size of the detector (10 cm in length), the two sides of the beam were obtained separately and superimposed. The experimental agreement with the theoretical shape is excellent.

\section{B. Rocking Curves}

A crucial test of the alignment is the comparison between the experimental and theoretical rocking curves. This cannot be done with a position-sensitive detector because for optimum resolution the full width of the incident beam is only six to eight channels. This relatively coarse measurement of the beam profile was insensitive to calculations of various predicted curves. At best, a geometric prediction 


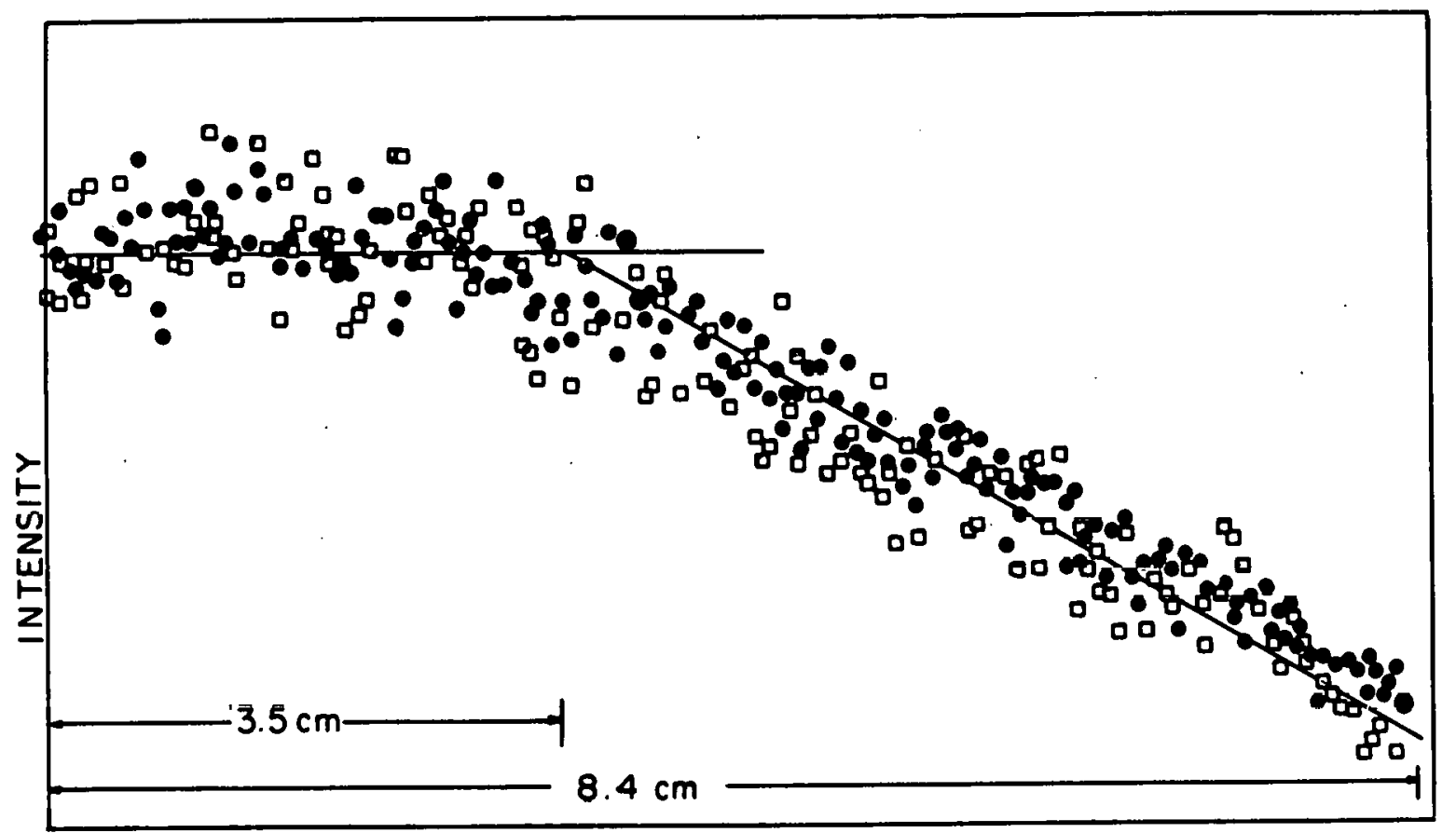

Fig. 16. Horizontal beam profile at the rear flange. lefthand side; $\square$ right-hand side. The solid line is geometrically predicted.

of the beam size at the detector was compared to that obtained geometrically. The width of the beam predicted and observed was $1.5 \mathrm{~mm}$. Despite this limitation, the data are sufficient to determine the centroid of the incident beam to a fraction of a channel as is described in the next section.

\section{DETERMINATION OF THE ZERO OF ANGLE}

One characteristic of a Kratky collimation system is the asymmetric profile of the 1ncident $x$-ray beam. Because of this the center of gravity of the beam (i.e., the zero of angle) must be determined experimentally. Using standard step-scanning equipment this can be done easily by scanning through the beam with subsequent integration and determination of the first moment of the profile. However, this could not be done with the IDPSD used in this study for two reasons. 
First of all, there was no easy method available for obtaining a beam profile without disturbing the system due to the positioning of the tungsten beam stop. Secondly, as mentioned previously, only six to eight channels are subtended by the beam which permit only a coarse integration of the profile. In addition to these, since the apparatus was aligned at low power settings, the profile of the beam could change during the power increase $(28 \mathrm{kV}, 30 \mathrm{~mA})$ due to a focal spot heating. Consequently, an alternate method using a scattering sample was employed.

The sample selected for this purpose was a dry, uranyl-acetate stained duck-tendon specimen. Stinson et al. ${ }^{14}$ have shown that up to seven orders of diffraction maxima were clearly visible in the low angle region. A scattering profile obtained on the same specimen with the apparatus used in this study is shown in Fig. 17. As can be seen up to the eleventh order was visible. This pattern was obtained with the vacuum chamber offset such that the tungsten beam stop was well below the incident beam. Insted, a piece of lead was uscd as an

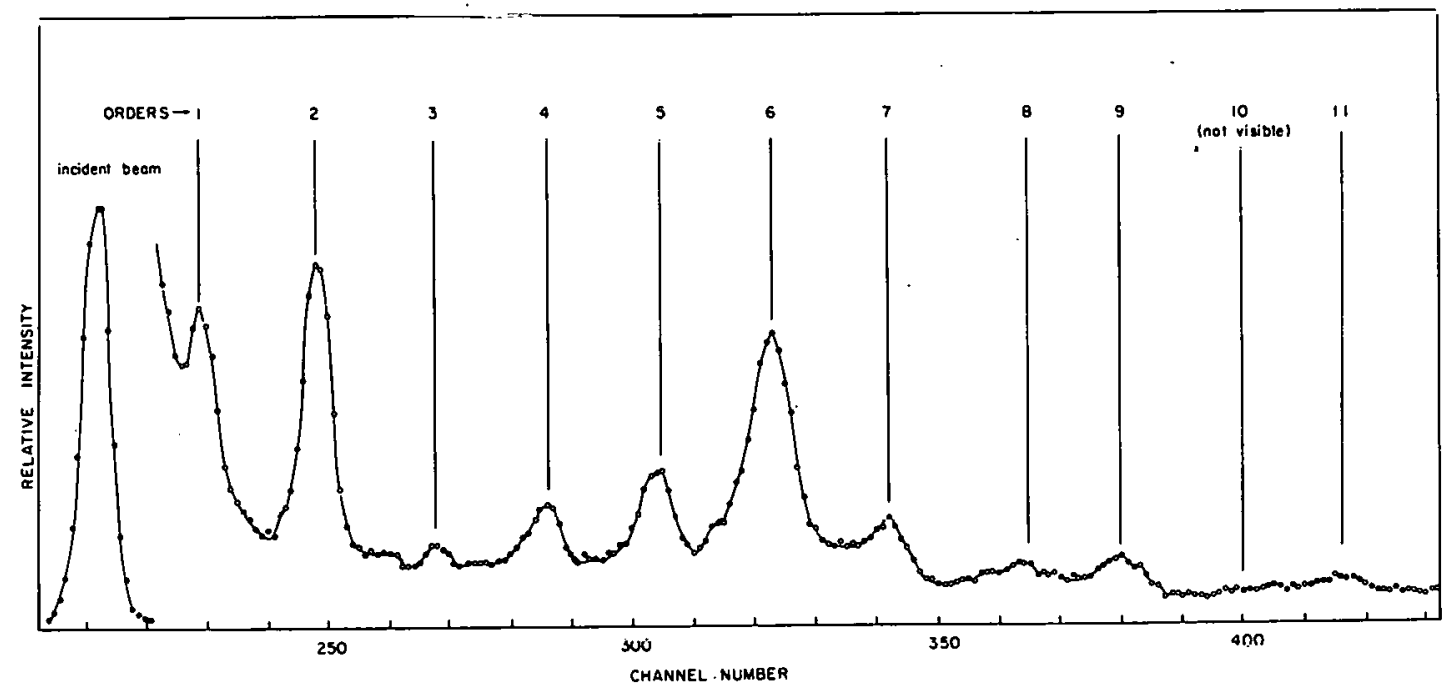

Fig. 17. Uranyl acetate stained duck tendon (with incident beam). 
external beam stop. Subsequently, a main beam profile (nickel attenuated) was obtained with exactly the same geometry without the sample and lead beam stop. In this way the zero of angle could be calculated by integration of the main beam profile and by an extrapolation to the zeroth order diffraction peak. The two methods agreed to within 0.25 channel which corresponds to 0.05 mradian. This agreement is considered to be excellent and thus permits this specimen to serve as a standard for angular calibration. Experiments on this sample were a1so performed on a step-scanning Kratky apparatus where a much finer integration of the beam was permitted; agreement to $<0.006$ mradian was found.

\section{NOISE LEVEL AND PARASITIC SCATTERING}

The system's performance was characterized in three different. ways. First of all, the apparatus should have a low noise level and minimal parasitic scattering, which are characteristic of the Kratky geometry. Secondly, the system's performance was compared to several other existing cameras using samples of monerate srattering intensity. Thirdly, the apparatus should be able to resolve weakly scattered intensities.

One distinct advantage of a 1DPSD over a conventional stepscanning apparatus equipped with a proportional counter is that, although the electronic nolse per unit time is approximately the same in both cases, the 1DPSD distributes the noise over the entire angular range. Therefore, if 100 channels were being used on the MCA the electronic noise and background would be 100 times less per angular reading on the 1DPSD than with a conventional detector. This apparatus was found to 
have a total background (including electronic noise) of 1 to 3 counts/s corresponding to a noise level of 0.01 to 0.03 count/s/channel.

With the camera aligned as described above, the scattering curve for the empty camera should exhibit an extremely rapid drop in intensity at very low angles, leveling off at the electronic noise. This characterizes the parasitic scattering and coupled with the slit width sets the experimental resolution. A typical blank run is shown in Fig. 18. These results should be compared with the parasitic scattering curve for

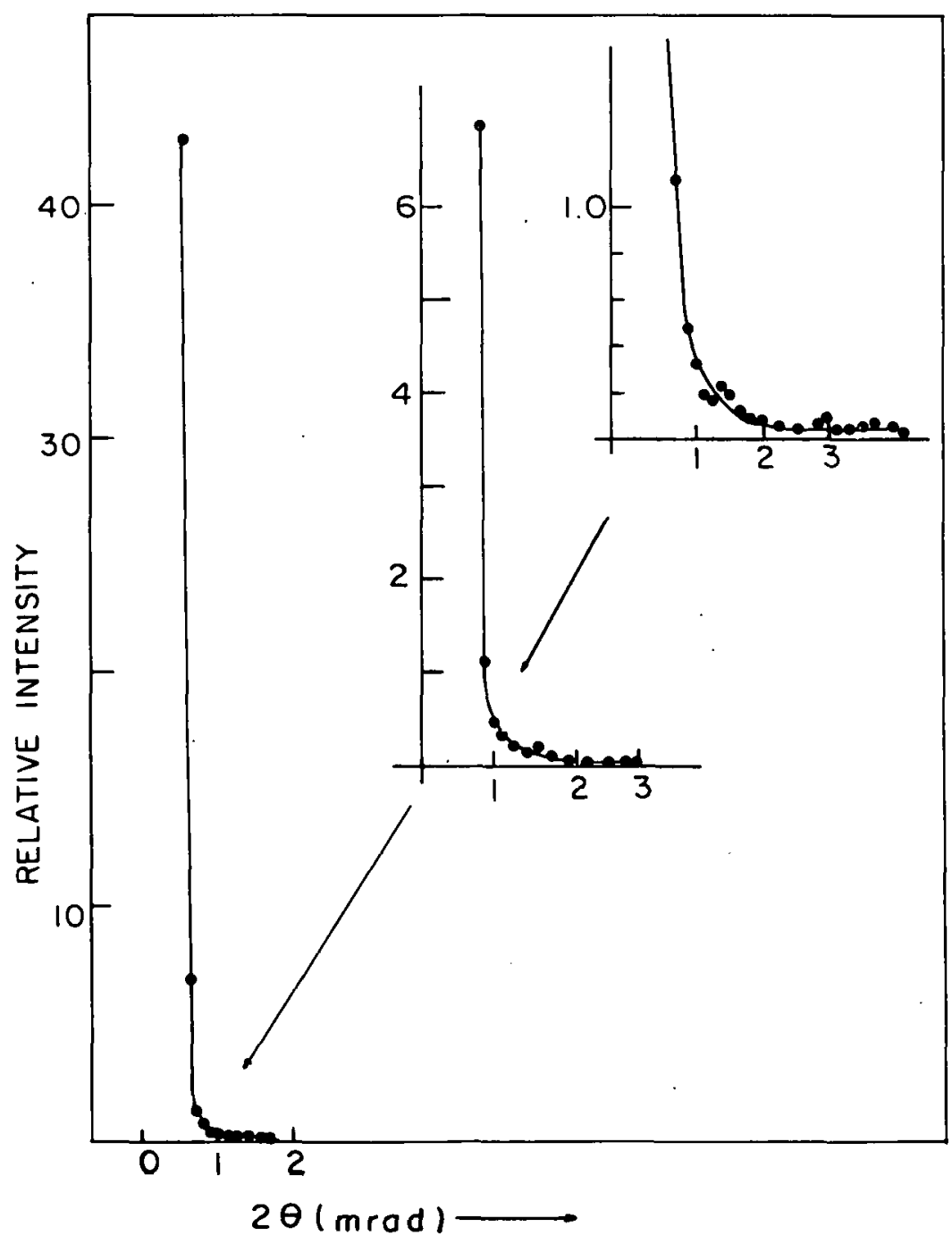

Fig. 18. Parasitic scattering of modified Kratky camera with 1DPSD. 
a normal Kratky camera presented by Hendricks.ll It is clearly seen that the predominant parasitic scattering occurs below 1 mradian. However, a low intensity tailing off was found to be present extending to 2-3 mradians. The exact origin of this could not be determined. It could not be attributed to a misalignment since the intensity is much too low. In fact, because the electronic noise of the present system is lower than any detector previously used on a Kratky camera, it is possible that this effect is present, but unresolvable, in all cameras. One possible explanation of the effect is that high energy radiation was impinging on the rear wall of the detector and fluorescing the aluminum or impurities in either the aluminum or the beryllium window. The fluorescent radiation could be of an energy that would be passed by the discriminator. As will be shown, this effect did not affect the analysis of the weak scatterers.

\section{DEAD-TIME CORRECTIONS}

Dead-time corrections were applied to all the 1DPSD data. This correction is associated with the counting capacity of the detector and associated electronics in which counts are lost due to the total number of events accumulated over the entire detector. This is the standard correction applied to any proportional counter. Following Chipman ${ }^{15}$ the dead time, $\tau$, was found from a plot of the ratio of an attenuated count rate $\left(I_{0}\right)$ to a nonattenuated count rate $\left(\mathrm{I}_{0}^{0}\right)$ versus the total count rate as shown in Fig. 19. The dead time is given by

$$
\tau=(\text { slope }) /\left(R_{t}-1\right)
$$

where $R_{t}$ is the intercept at zero count rate. For this system $\tau=14 \mu \mathrm{s}$. 


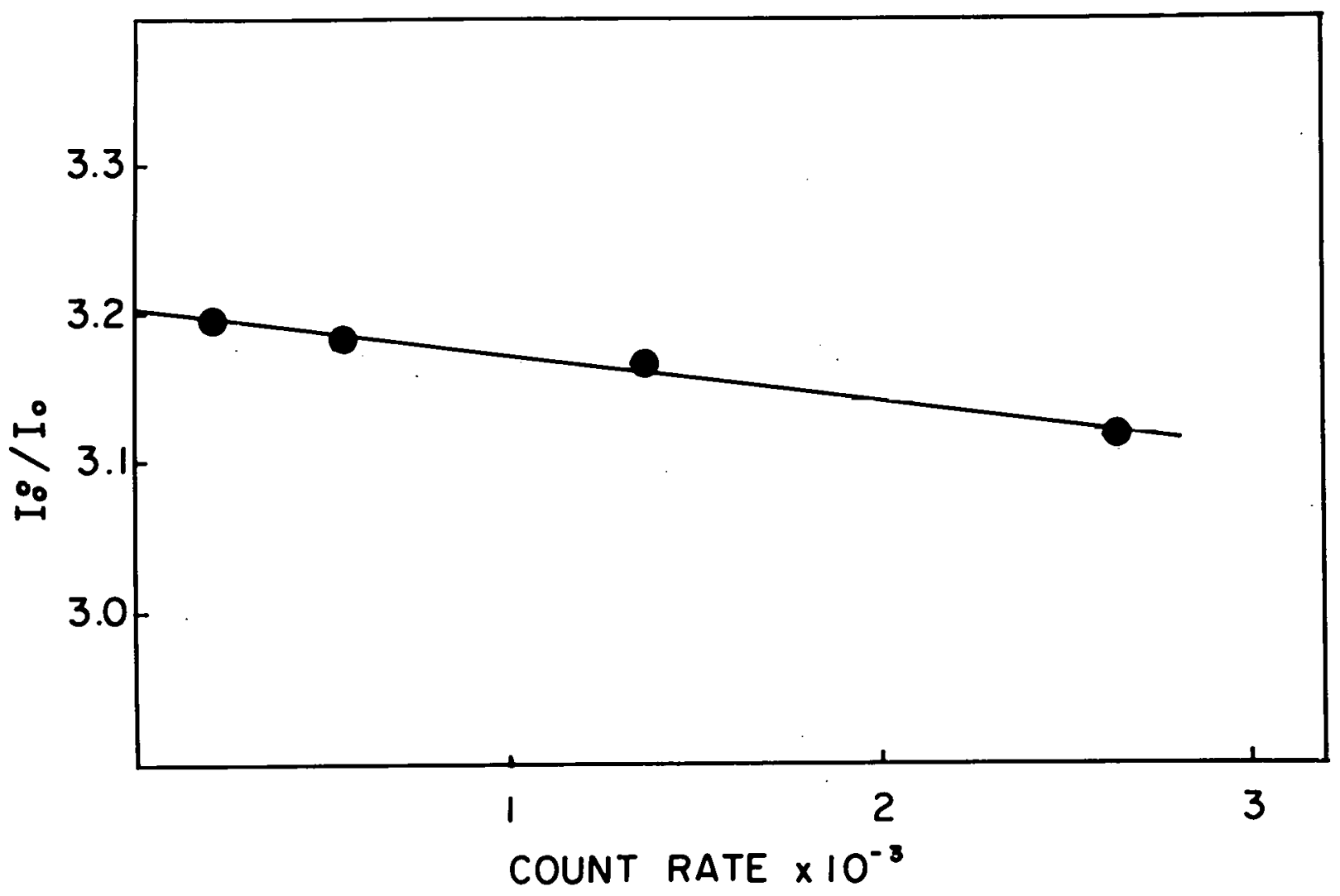

Fig. 19. Data for dead-time correction by method of Chipman. 15 The count rate is in thousands/s.

This correction, applied to the total number of counts, yields a factor by which each channel intensity is multiplied independent of channel number.

$$
I_{i, \operatorname{corr}}=\frac{I_{i, o}}{1-\sum_{i} I_{i} \tau}
$$

where $I_{i, 0}$ is the observed counts and $I_{i, \operatorname{corr}}$ is the counts in channel $i$ corrected for the overall dead time, $\tau$, and $\sum_{i} I_{i}$ is the sum of all the counts in all the channels used. This method of dead-time measurement includes the effects of all components of the detector system including those of the multi-channel analyzer. For the samples of interest in the present investigations, the dead-time correction was not significant. 


\section{COMPARISON WITH OTHER EQUIPMENT}

The performance of the camera described in this report was compared to that of other small-angle x-ray scattering instruments. Scattering profiles from several specimens were compared to those obtained on: (1) the ORNL 10-m SAXS camera, ${ }^{1}$ (2) a Bonse-Hart system, 16 and (3) in an international absolute intensity calibration project. 17 The specifications of the various samples are given in Table 2 along with the system used for comparison.

Table 2. Sample Specifications for Intercomparison Experiments

\begin{tabular}{|c|c|c|c|c|c|}
\hline $\begin{array}{c}\text { Sample } \\
\text { Desrriptinn }\end{array}$ & 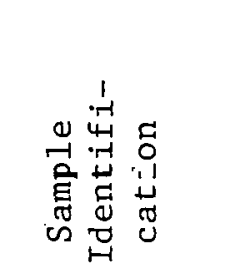 & 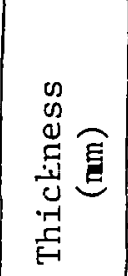 & 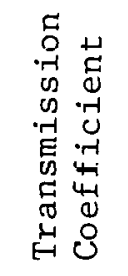 & 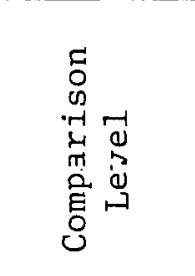 & $\begin{array}{c}\text { Comparison } \\
\text { to: }\end{array}$ \\
\hline Polyethylene & Marlex, PE & 1.26 & 0.367 & Relative & $\begin{array}{l}\text { Two-dimensional pattern } \\
\text { in point collimation }\end{array}$ \\
\hline Polystyrene & PS -3 & 1.002 & 0.217 & Absolute & IUCr project ${ }^{17}$ \\
\hline Glassy carbon & $\mathrm{GC}-3$ & 1.831 & 0.315 & Relative & IUCr project ${ }^{17}$ \\
\hline $\begin{array}{l}\text { Polyvinyl- } \\
\text { chloride }\end{array}$ & PVC & 0.530 & 0.325 & Absolute & Bonse-Hart 16 \\
\hline
\end{tabular}

Initially an attempt was made to place all the scattering profiles on an absolute basis by measuring the power of the incident beam via the multiple foil technique. However, in performing the comparison with the ORNL 10-m SAXS camera using a polyethylene specimen the absolute intensities were not in agreement. Therefore, the same polyethylene specimen was used as a secondary standard with subsequent calibration against a 
Kratky Lupolen specimen ${ }^{19}$ with satisfactory results. The discrepancy, although disturbing, could possibly be associated with space charge effects. This effect, as will be discussed later, arises when there is a localized region of high intensity. As mentioned previously, the incident beam is confined to six to eight channels on the MCA and even with attenuation this localized beam is very intense.

Before discussing the various scattering profiles, the overall power specifications of our device are compared to those of a normal step-scanning Kratky camera and the ORNL 10-m SAXS camera. ${ }^{1}$ Table 3 shows this comparison. Column 4 contains the specifications of the current 1DPSD Kratky system, column 3 contains these same specifications when the entrance slit has been normalized to that of the step-scanning Kratky in column 2, and column 5 typifies the power of the 2DPSD facility.

\section{A. Comparison with the ORNL 10-m SAXS Camera}

A sample of Marlex (polyethylene) was used to compare the 1DPSD system with the 2DPSD system. Before the comparison could be performed the data from the IDPSD system, as recorded in the MCA, had to be reduced to yield the intensity profile as a function of scattering angle. A FORTRAN IV program was developed to perform this task. Once the angular intensity was obtained, the data were desmeared to reduce the data to that which would have heen obtained with a pinhole geometry. This was done using the desmearing procedure of Schmidt $^{20}$ assuming an infinite slit-length geometry.*

\footnotetext{
*This assumption is valid because, as is seen from Fig. 20, the scattering from Marlex decreases to essentially zero within 15 mradians, whilc from Fig. 16 it is seen that the incident beam is constant to $35 / 1545=22$ mradi.ans.
} 
Tatle 3. Comparison of Equipment

\begin{tabular}{|c|c|c|c|c|}
\hline Property & $\begin{array}{l}\text { Step } \\
\text { Scanning }\end{array}$ & $\begin{array}{l}\text { Kratky Camera } \\
\text { 1DPSD Normal- } \\
\text { ized to Step } \\
\text { Scanning }\end{array}$ & 1DPSD & $\begin{array}{l}\text { 10-m Small Angle } \\
\text { X-Ray Scattering } \\
\text { Cameral }\end{array}$ \\
\hline $\begin{array}{l}\text { RADIATION CHARACTERIふTICS } \\
\text { X-Ray Source }\end{array}$ & Siemens & s special Kratky tute - & $\longrightarrow$ & $\begin{array}{l}\text { Rigaku Denki } 6 \mathrm{~kW} \\
\text { rotating anode }\end{array}$ \\
\hline $\begin{array}{l}\text { Focal spot size, } \mathrm{mm}^{2} \\
\text { Power }(\mathrm{kV}, \mathrm{mA})\end{array}$ & $\begin{array}{l}2.8 \times 7 \\
(40,30)\end{array}$ & $\begin{array}{l}2.8 \times 7 \\
(40,30)\end{array}$ & $\begin{array}{l}2.8 \times 7 \\
(38,30)\end{array}$ & $\begin{array}{l}0.5 \times 5 \\
(45,100)\end{array}$ \\
\hline Monochromator & $\begin{array}{l}\text { Graphite (dif- } \\
\text { fracted beam) }\end{array}$ & $\begin{array}{l}\text { Nickel filtered } \\
\text { (incident) }\end{array}$ & $\begin{array}{l}\text { Nickel filtered } \\
\text { :incident) }\end{array}$ & $\begin{array}{l}\text { Graphite } \\
\text { (incident) }\end{array}$ \\
\hline $\begin{array}{l}\phi \text {, apparent bril- } \\
\text { liance of focal spot } \\
\text { (photons } \mathrm{s}^{-1} \mathrm{sr}^{-1} \mathrm{~mm}^{-2} \text { ) }\end{array}$ & $0.32 \times 10^{12}$ & $0.36 \times 10^{12^{*}}$ & $0.26 \times 10^{12}$ & $8 \times 10^{12}$ \\
\hline \multicolumn{5}{|l|}{ COLLIMATION CONDITIOHS } \\
\hline $\begin{array}{l}\varepsilon_{\text {min }} \text {, minimum angle to } \\
\text { which data are col- } \\
\text { lected (mradian) }\end{array}$ & 2.52 & & 1.0 & 0.4 \\
\hline $\begin{array}{l}\mathrm{F}_{1} \text {, area of entrance } \\
\text { slit }\left(\mathrm{mm}^{2}\right)\end{array}$ & $0.098 \times 10=0.98$ & $0.098 \times .10=0.98^{*}$ & $0.065 \times 10=0.65$ & $\frac{\pi}{4}(1)=0.79$ \\
\hline $\begin{array}{l}\Delta \Omega_{1} \text {, solid angle of } \\
\text { incident beam }(\mathrm{sr})\end{array}$ & $\frac{0.222 \times 18}{(288)^{2}}=4 \varepsilon \times 10^{-5}$ & $\frac{0.256 \times 19}{(298)^{2}}=54 \times 10^{-5 *}$ & $\frac{c .17 \times 19}{(298)^{2}}=36 \times 10^{-6}$ & $\frac{0.79}{(5000)^{2}}=32 \times 10^{-9}$ \\
\hline $\begin{array}{l}\Delta \Omega_{2} \text {, solid angle of } \\
\text { receiving slit (sr) }\end{array}$ & $\frac{0.633 \times 10}{(259)^{2}}=94 \times 10^{-6}$ & $\frac{0.4 \times 10}{(1543.6)^{2}}=1.7 \times 10^{-6}$ & $\frac{c .4 \times 10^{4}}{(1543.6)^{2}}=1.7 \times 10^{-6^{\dagger}}$ & $\frac{(200 / 64)^{2}}{(5000)^{2}}=39 \times 10^{-8^{\dagger}}$ \\
\hline $\begin{array}{l}\mathrm{P}_{0} \text {, power of beam bath- } \\
\text { ing specimen (photon } s^{-1} \text { ) }\end{array}$ & $15 \times 10^{6}$ & $19 \times 10^{6^{*}}$ & $6.1 \times 10^{16}$ & $1.0 \times 10^{6}$ \\
\hline
\end{tabular}

* Normalized according to entrance slit width and power. ${ }^{\dagger}$ Sterad per detector element. 
The comparison of the two scattering curves obtained on each instrument is shown in Fig. 20. As can be seen, the curves differ by up to $10 \%$. Schelten and Hendricks ${ }^{8}$ noted similar differences in a previous publication. These authors outlined four possible sources of the discrepancies between the scattering profiles - (1) failure to correct the data for s1,it-width smearing, (2) systematic errors resulting from nonsimultaneous detection, (3) systematic errors in the slit-length desmearing procedure, and (4) nonuniformities of the sample. It is to be noted that the data obtained with the 2DPSD were not corrected for collimation errors, and because of the extent of the electronic resolution,

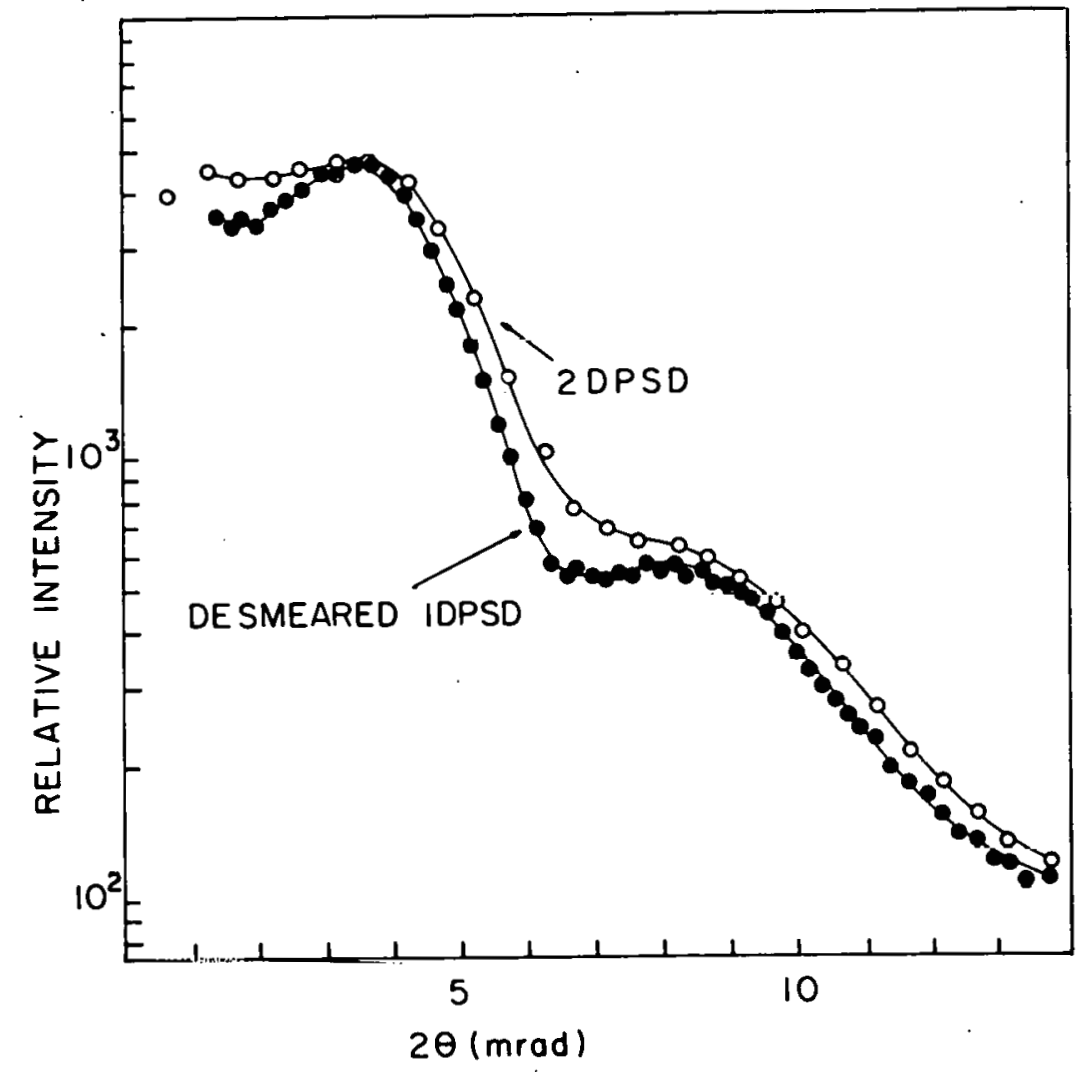

Fig. 20. Scattering curves for Marlex (polyethylene) as determined on the 10-m SAXS camera in point collimation $(O)$ and on the present device, after collimation correction $(\bullet)$. 
these effects are not entirely negligible. The use of position-sensitive detectors for both runs eliminated the second effect. The possibility of systematic errors in the desmearing procedure or nonuniformity in the specimen still remains. Despite the differences, the agreement should be considered as being very good.

\section{B. Comparison with a Bonse-Hart System}

A polyvinylchloride (PVC) sheet was used for this comparison. PVC is a very weak scatterer with a high attenuation factor duc to the high concentration of chlorine. The scattering observed from PVC arises from two sources. The first, which is an angularly independent scattering, is due to thermal density fluctuations, as discussed by Straff and UhImann ${ }^{16}$ and Wendurff and Fischer. ${ }^{21}$ Superimposed on this is a very low-angle scattering arising from heterogeneities within the sample. The purpose of this report is to recognize the presence of this lowangle scattering and is not intended to determine the nature of these heterogeneities.

The smeared data obtained with the 1DPSD is shown in Fig. 21 along with the data of Straff and Uhlmann. ${ }^{16}$ As can be seen, the 1DPSD data agree in the outer regions of the scattering profiles; however, in the very low-angle section the 1DPSD data lie slightly below the data of Straff and Uhimann. ${ }^{16}$ In light of their work this angular dependent scattering can be described by

$$
I=c(1-c) V(\Delta \rho)^{2} \exp \left(-R_{g}^{2} h^{2} / 3\right)
$$




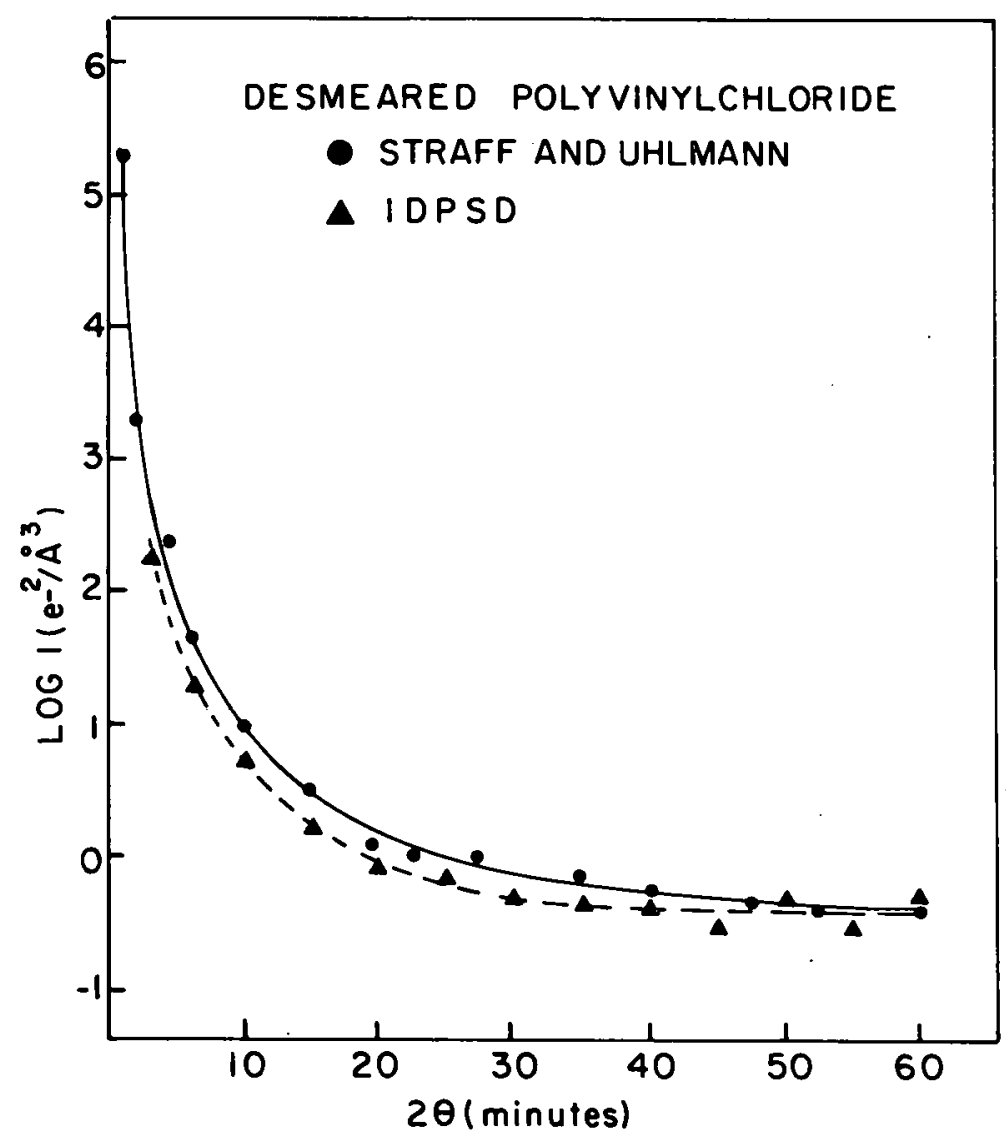

Fig. 21. Comparison of scattering from polyvinylchloride as determined by Straff and Uhlmann ${ }^{16}(\bullet)$ on a Bonse-Hart camera and in the present work (A).

where $c$ is the concentration of heterogeneities of radius $R_{g}$ characterized by an electron density difference relative to the matrix of $\Delta \rho$. Since the PVC used in this study was purified and that of Straff and Uhlmann was not, it is reasonable to expect that the two curves should not be identical. However, simply by varying $c$ and $R_{g}$, Eq. (4) can be used to describe both curves.

It will also be noted that. the data of Straff and Uhlmann extend to smaller scattering angles than the data obtained here. This is a rcoult of the differenr.p hetween the Kratky and Bonse-Hart apparatus. 22 
However, the resolution lost by use of the Kratky camera is minimized and is compensated by a higher intensity. It is concluded that the IDPSD system developed here displays a very good agreement with the Bonse-Hart apparatus.

\section{Comparison with Other Kratky Geometries}

Prubably the most critical comparison to be performed is that between the 1DPSD and other Kratky geometries. Provided identical specimens and resolutions are used, there should be no discrepancies. Such a comparison was easily conducted using the polystyrene and a glassy carbon sample prepared for the International Union of Crystallography's Commission on Crystallographic Apparatus International Project for the Calibration of Absolute Intensities in SmaZl-Angle X-Ray Scattering as described by Hendricks et al.17 Comparisons with both samples were performed on the smeared scattering intensities to eliminate the possibility of desmearing errors.

(a) Polystyrene Comparison

The polystyrene specimen (PS-3) scattering profiles obtained from the IDPSD and as published in the IUCr report are shown in Fig. 22. As can be seen the two profiles superimpose. This result is reassuring and indicates that any difterences encountered with prior comparisons are not due to the apparatus and must be attributed to other genuine sample differences or to subsequent data treatment. 


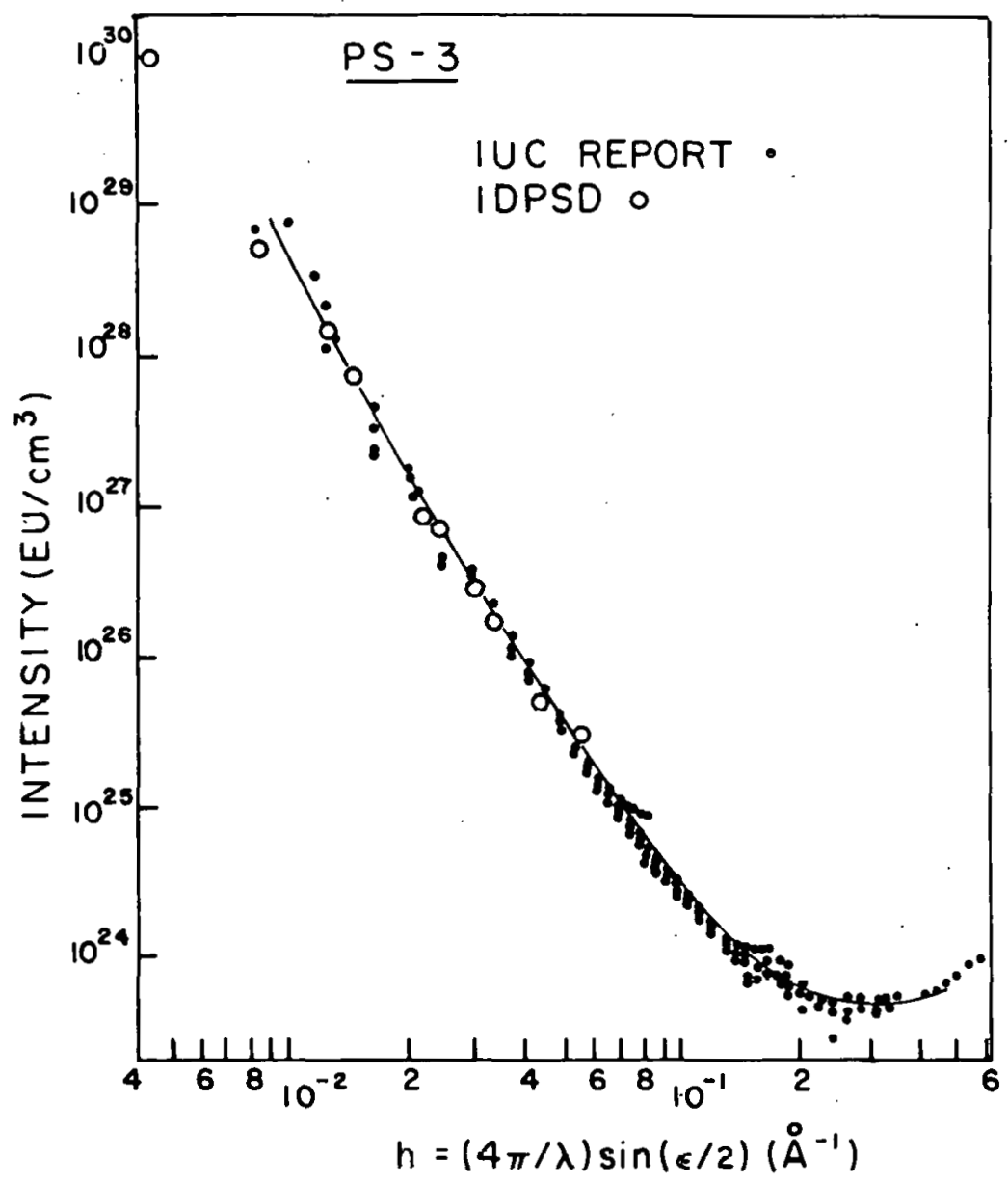

Fig. 22. Comparison of scattering curves for polystyrene (PS-3) determined by numerous investigators participating in an IUCr absolute. intensity project on a variety of instruments ${ }^{17}(0)$ and that obtained in the present work (O).

(b) Glassy Carbon Comparison

Up to this point the various specimens investigated scattered in the very weak (PVC) to moderate (Marlex) range. A glassy carbon specimen was chosen to study the effect of very strong scatterers. The scattering from glassy carbon originates from a high concentration of voids, and is among the most intense observed at very low angles.

Quite surprisingly, the spectrum obtained from the 1DPSD system contained a scattering peak at approximately 3 mradians. This result 
is in error because the well-established scattering curve from this glassy carbon specimen $(\mathrm{GC}-3)$ is monotonically decreasing. ${ }^{17}$ Repeated experiments on the IDPSD produced identical results. As will be discussed shortly, this peculiar spectrum of the GC-3 specimen can be attributed to space charge effects in the detector. Upon attenuating the beam and counting for longer times, a glassy carbon spectrum was obtained that had the same angular dependence of intensity as that of the IUCr report ${ }^{17}$ (not shown here).

\section{Comments on the Comparisons}

Despite the various problems encountered during the performance tests of the modified Kratky collimation system with the 1DPSD described here, it has been shown that, provided sufficient care is taken, the results are essentially the same as those obtained on any other scattering facility. Agreement was found with a very wide range of scattering specimens on a wide and varied range of equipment. However, as will be discussed, extreme caution must be exercised when intense scatterers are being investigated.

\section{SPACE CHARGE EFFECTS}

The phenomenon of space charge effects in non-position-sensitive proportional counters has been understood for some time.23-2€ basicaliy, when count rates are high in a localized region, the slowly moving positive charges created by a preceding event shield the anode wire from the electrons created in a succeeding event, thus lowering the effective potential on the anode. This causes a decrease in the gas amplification 
factor and a broadening of the energy resolution. A quantitative theory of this effect has been developed by Hendricks. ${ }^{26}$ Although the effect of space charges has not been worked out quantitatively for positionsensitive detectors, qualitatively. several effects on the spatial resolution are to be expected. First, a localized region of high count rate. (as would be expected at a Bragg reflection, for instance) will cause a distortion of the normally radial electric field lines which will cause a focusing of the in-coming electrons toward the positive ion cloud (Fig. 23). Such a focusing would be expected to distort the shape of a scattering curve. Secondly, the localized reduction in apparent potential

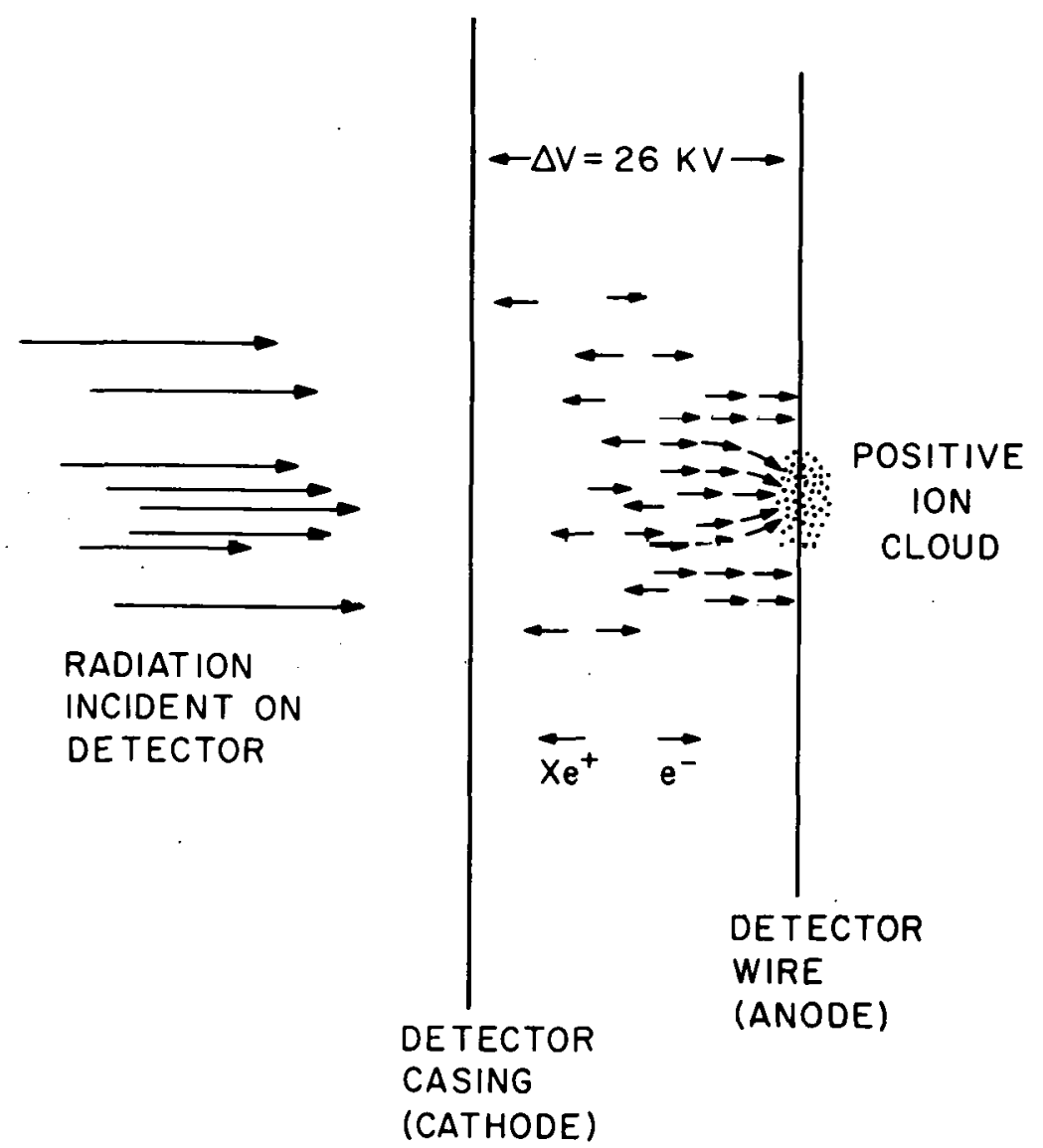

H'ig. 23. Space charge effecr: deflection of elecliuis. 
between the anode and cathode is expected to cause a position-dependent decrease in the gas amplification factor, thus causing an apparent loss of photons due to energy discrimination.

We present below our first experimental results demonstrating the effect of space charge in 1DPSDs. The sample used for this investigation was a glassy carbon specimen (GC-3, as described in ref. 17) which at a source power setting of $28 \mathrm{kV}$ and $30 \mathrm{~mA}$ had an integrated scattering of $200-250 \mathrm{k}$ counts/s. The intensity profile is characterized by an exponential increase in intensity at very low angles.

The scattering curves shown in Fig. 24 were obtained under two different conditions. Spectrum A (full circles) was obtained with the full power of the main beam impinging on the specimen, whereas with spectrum B (open circles) the main beam was attenuated $(\times 1 / 80)$ with nickel foils. The recording times were 5 and $400 \mathrm{~s}$, respectively. The profiles were obtained so as to normalize the tail region of the curves. As can be seen, the two profiles are virtually identical except in the 0 to 5 mradians region where the count rate is quite high. At the smallest angles spectrum $A$ has a lower count rate than spectrum $B$ but at slightly higher angles then it exceeds $B$, and develops a maximum. As discussed above and in detail by Hendricks ${ }^{26}$ the initial, very significant reduction in the recorded intensity is the result of a change in the local electric field resulting in a count rate loss due to energy discrimination. At somewhat higher angles (3-4 mradians), the intensity of the distorted spectrum actually rises above that of the undistorted, low count rate spectrum. This can be accounted for by the focusing effect of the space charge cloud (described above) attracting electrons 


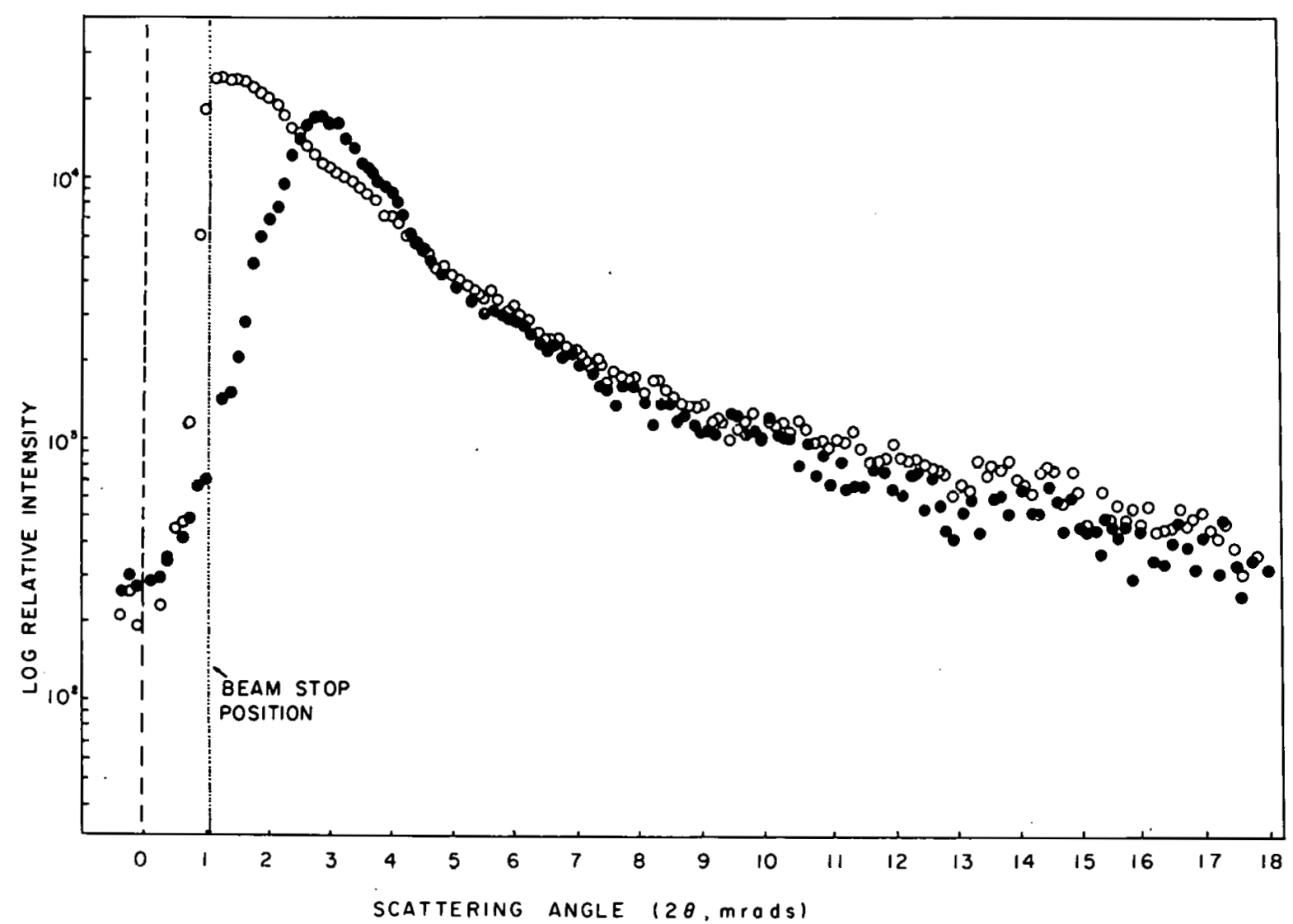

Fig. 24. Scattering curves for glassy carbon as determined with the present apparatus at two different integrated count rates. 5-s count time; $O$ 400-s count time. The differences are due to space charge effects.

from events which occurred at somewhat higher angles into the low-angle regi.on.

An important point to be made here is that the excess intensity observed at about 5 mradians with the IDPSD would not be observed with a normal. step-scanning apparatus and a non-position-sensitive detector. With the latter device the deflected electrons would still be included in the accumulated counts at that angle, whereas with the 1DPSD these deflected electrons are included in the total events occurring at another position on the wire corresponding to another angle. Therefore, a conventional apparatus would only experience a loss in intensity due solely 
to the apparent loss of photons caused by a change in the electric field at the wire and their resultant rejection by the energy discriminator. Aside from the effects described above, space charges can also affect the determination of system dead times. In the method of Chipman ${ }^{15}$ the parameters of interest are the total count rate $\left(\mathrm{I}_{0}^{0}\right)$ and an attenuated count rate $\left(I_{0}\right)$. If a scatterer such as $\mathrm{GC}-3$ is used to obtain these parameters, then there can be losses in the count rates due to the space charges. The ratio $\left(I_{0}^{0} / I_{0}\right)$ determined at high count rates can be decreased considerably causing an erroneously high $\tau$. Figure 25 clearly illustrates such effects. Using only points at the

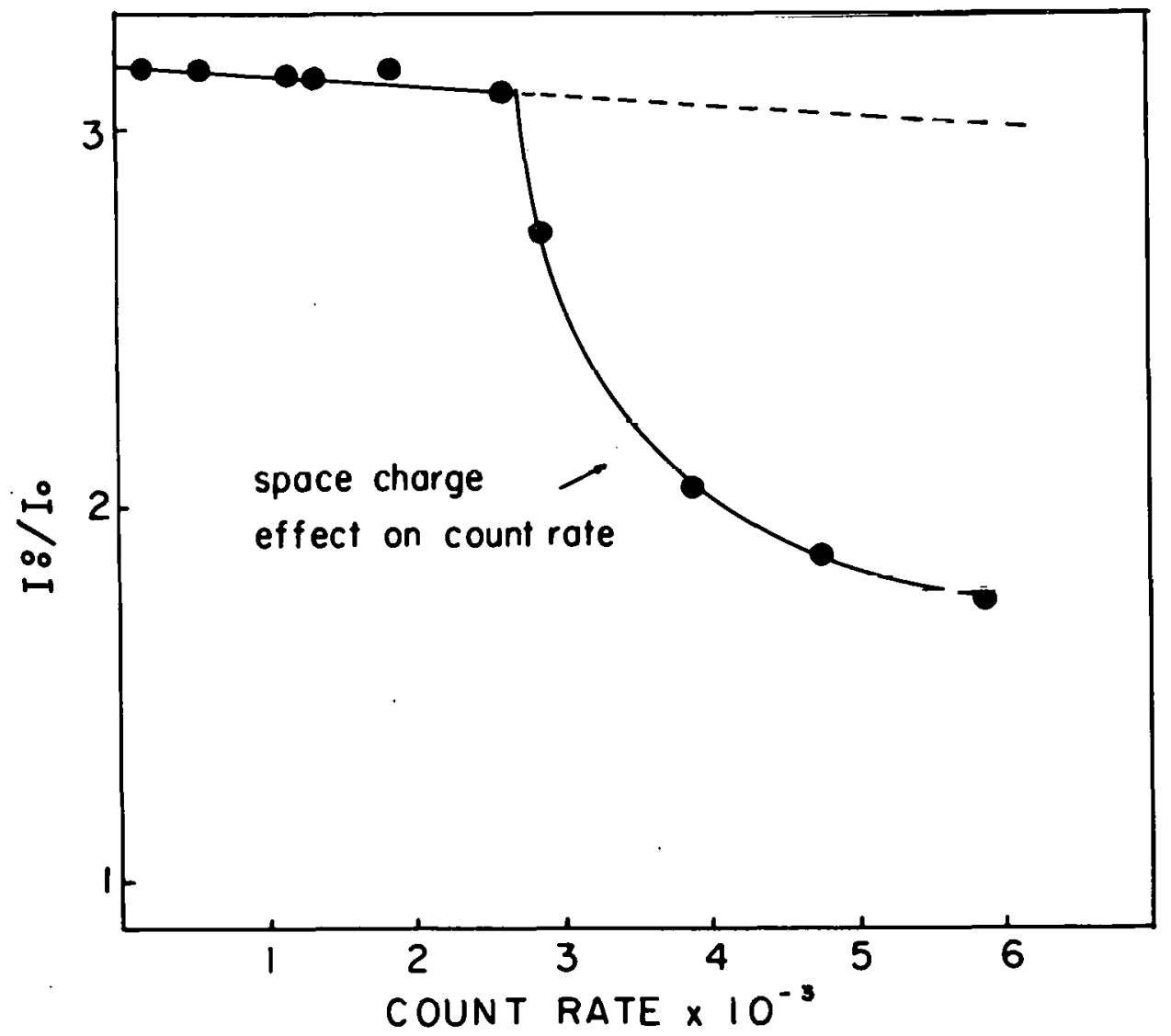

Fig. 25. Effect of space charge on dead time experiment. Count rate in counts per second. 
extreme ends of the curve leads to a dead time of $140 \mu$ s rather than the correct value of $14 \mu \mathrm{s}$. This problem can be circumvented by using a scatterer with a fairly uniform profile so that there are no areas with extremely intense scattering.

\section{FILL-GAS EFFECT}

The detector used in this study was filled with a mixture of $97 \% \mathrm{Xe}-3 \% \mathrm{C}_{3} \mathrm{H}_{6}$. The reason $\mathrm{C}_{3} \mathrm{H}_{6}$ (cyclopropane) was used as a quenching gas rather than $\mathrm{CO}_{2}$ was because $\mathrm{C}_{3} \mathrm{H}_{6}$ is much faster and leads to higher spatial and energy resolution. However, organic gases have a serious drawback in comparison to gases like $\mathrm{CO}_{2}$ because they are decomposed and polymerized, especially at high gas amplification. When decomposition occurs, the detector wire is coated (usually not uniformly) with a dielectric carbonaceous material and/or carbon thus altering the resistivity and diameter and reducing the electric field (locally) and consequently causing a drop in gas amplification of the incident electrons in that region. When a discriminator is used, then this causes a reduction in the count rate in the regions that are coated with the decomposition products of the quench gas. This was seen in the scattering profiles of a series of blends of poly(p-iodostyrene) with polystyrene diluted in poly(p-iodostyrene). In Fig. 26 profiles are shown with and without this effect. This problem can be avoided by two different routes. If it is desirable to use fairly tight energy discriminators then the detector must be shifted physically such that the coated area of the wire is below the beam stop. If the discriminator setting is not critical, then the lower energy level can be decreased 


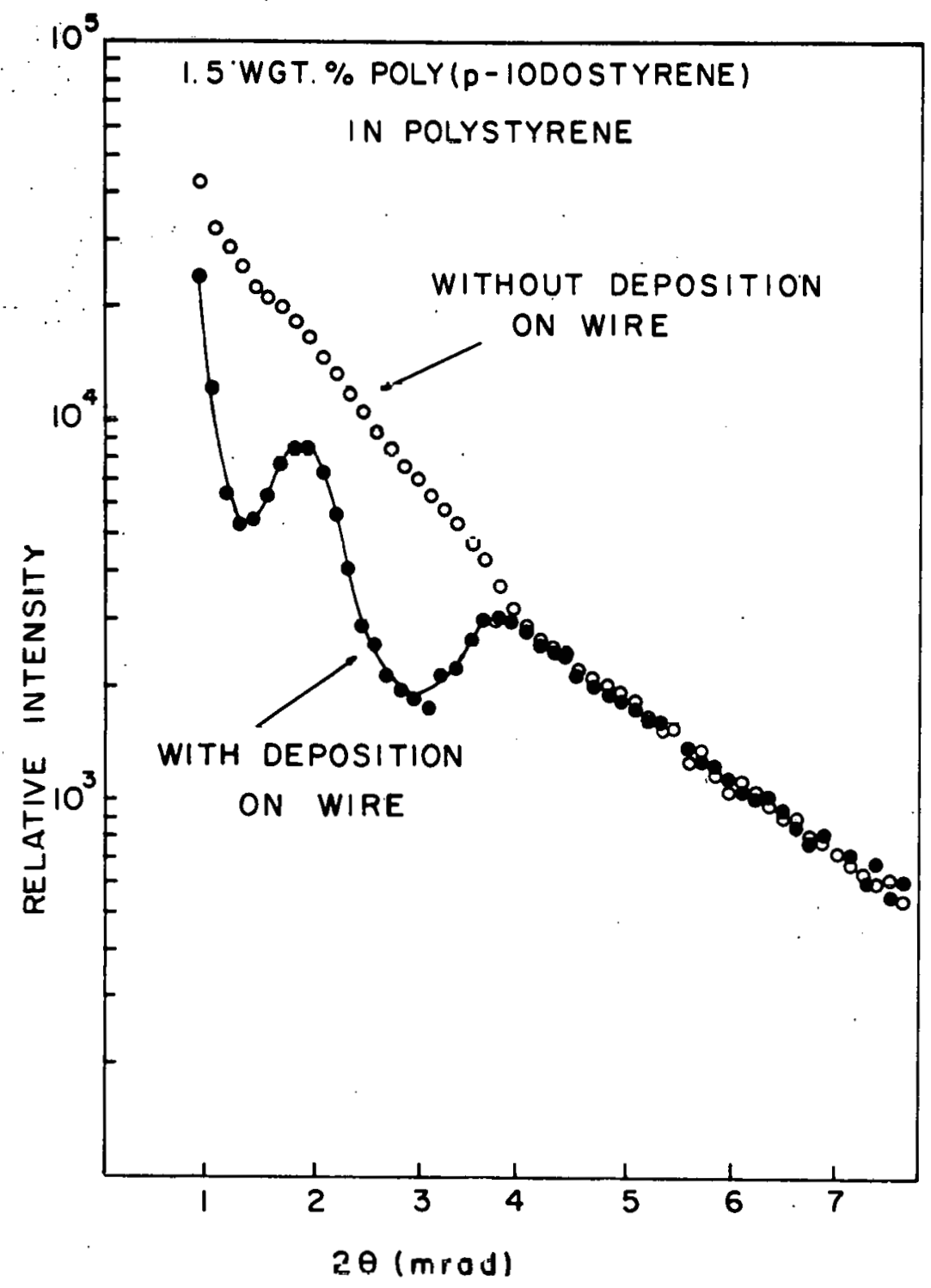

Fig. 26. Poly(p-iodostyrene): effect of fill-gas decomposition.

and the window can be opened to allow all the counts of interest to be acquired. In this way the effect can still be eliminated to some extent. However, a possibly more desirable method is to use $\mathrm{CO}_{2}$ as a quench gas and apply a higher voltage to the detector to increase the resolution. 


\section{COMMENTS AND RECOMMENDATIONS}

The one-dimenstonal position-senstive detector used in confunction with a Kratky camera resulted in a small-angle x-ray scattering facility with both high resolution and low parasitic scattering. The facility was capable of resolving the scattering profiles of weak scatterers, such as PVC, as well as very intense scatterers, such as glassy carbon. During the course of this investigation several areas where precautions must be taken, not only with this facility but with positionsensitive detectors in general, were discerned.

As with most facilities and equipment, retrospective views give rise to areas of improvement. The apparatus described here is no different, and we make several recommendations. below.

\section{A. Fill Gas}

As discussed in the previous section, the cyclopropane gas could be replaced with $\mathrm{CO}_{2}$ to reduce the problems associated with deposition of decomposition products on the wire. It is to be noted that $\mathrm{CO}_{2}$ also decomposes at high gas amplification but at a much slower rate.

\section{B. Detector Wire}

Although not emphasized in this report, the wire used in the detector described in Sect. II was a carbon-coated quartz fiber. A serfous drawback to this design is that the wire can easily be destroyed by direct exposure to the incident beam. This will cause a local evaporation of the carbon coating and consequently affect the uniformity of the wire by changing the resistance at that point. If 
the wire is burned severely enough, this can cause a total failure of the detector. This problem is magnified with the use of a Kratky-type collimation system since the full power of the $x$-ray beam must be placed close to the edge of the tungsten beam stop in order to achieve resolution.

During the course of this study the detector was burned to only a minor degree in one position. This inhomogeneous position on the wire was avoided by physically lowering this section below the beam stop. However, ideally a detector wire that can withstand exposure to the inrident beam is desirable. At present a detertor equippod with a metal wire which meets these requirements is in the final stages of development and testing.

\section{Detector Resolution}

The resolution of the detector used in this study was $400 \mu \mathrm{m}$ and necessitated the use of the extended flight path. A detector with higher spatial resolution would have been much easier to work with since the flight path would have been shorter. This would make the system much less sensitive to vibrations and other minor disturbances. Alignment would be significantly easier. With the current geometry, alignment was difficult due to the size and mass of the flight path. Small changes in the positioning of the flight path caused significant changes in the bridge alignment. With a shorter geometry, these problems would be alleviated. 


\section{ACKNOWLEDGMENTS}

The authors are indebted to D. Shapira for his encouragement and suggestions throughout the course of this work; to R. H. Ward, R. Barnes, A. J. Millet, M. Ball and R. P. Cumby of Oak Ridge National Laboratory and C. Napikoski and J. Zolty of the University of Massachusetts for providing technical assistance during the construction of the system and F. A. Scarboro for preparing the manuscript. We express our appreciation to J. R. Weir, Jr., C. J. McHargue, H. L. Yakel, and A. Wohlpart for their administrative assistance in arranging the joint project between the University of Massachusetts and Dak Ridge National Laboratory. Finally, one of us (TPR) is particularly grateful to the Oak Ridge Associated Universities, Oak Ridge National Laboratory, and the Polymer Research Institute of the University of Massachusetts for their financial assistance. 


\section{REFERENCES}

1. R. W. Hendricks, J. App Z. C'ryst. 11, 15 (1978).

2. C. J. Borkowski and M. K. Kopp, Rev. Sci. Instrum. 39, 1515 (1968).

3. C. J. Borkowski and M, K. Kopp, IEEE Trans. NucZ. Sci. NS17, 340 (1970).

4. C. J. Borkowski and M. K. Kopp, IEEE Trans. Nucl. Sci. NS19, 161 (1972).

3. U. Kratky, Z̃. Electrochem., Ber. Bunsenges. Physik Chem. 58,49 (1954); 62, 66 (1958).

6. 0. Kratky, in SmaZZ-AngZe X-Ray Scattering (H. Brumberger, ed.), Proceedings of Conference held at Syraruse University, June 1965, Gordon and Breach, New York (1966).

7. R. W. Hendricks, J. App Z. Cryst. 5, 315 (1972).

8. J. Schelten and R. W. Hendricks, J. AppZ. Cryst. $\underline{8}, 421$ (1975).

9. R. W. Hendricks, J. T. DeLorenzo, F. M. Glass, and R. E. Zedler, J. App Z. Cryst. 6, 129 (1972).

10. M. K. Kopp and J. A. Williams, Rev. Sci. Instrum. 48, 383 (1977).

11. R. W. Hendricks, J. App Z. Cryst. $\underline{3}, 348$ (1970).

12. R. W. Hendricks, J. S. Arrington, and W. J. Mason, J. App Z. Cryst. $\underline{1}, 128$ (1968).

13. J. W. Anderegg, P. G. Mardon, and R. W. Hendricks, An Alignment Procedure for the Kratky Small-Angle X-Ray Comera, Oak Ridge National Laboratory Report ORNL-4476 (1970).

14. R. H. Stinson, M. W. Bartlett, T. Kurg, P. R. Sweeney, and R. W. Hendricks, Biophysical J. (submitted 1978).

15. D. R. Chipman, Acta Cryst. A25, 209 (1969).

16. R. S. Straff and D. R. Uhlmann, J. Polymer Sci.: Poly. Phys. Ed. 14, 353 (1976).

17. R. W. Hendricks and L. B. Shaffer, J. Appl. Cryst. 11, 196 (1978).

18. J. M. Schultz, J. S. Lin, and R. W. Hendricks, J. App Z. Cryst. 11, 551 (1978) 
19. 0. Kratky, I. Pilz, and P. J. Schmitz, J. ColZoid. Interface Sci. 21, 24 (1966).

20. P. W. Schmidt, J. App Z. Cryst. $\underline{3}, 137$ (1970).

21. J. H. Wendorff and E. W. Fischer, KolZoid Z.Z. Polymere 251, 876 (1973).

22. 0. Kratky and H. Leopold, Makromol. Chem. 133, 181 (1970).

23. D. K. Wilkinson, Ionization Chambers and Counters, Cambridge University Press, London (1950).

24. S. L. Binder and E. J. Rapperport, The EZectron Microprobe (T. D. McKinley et a1., eds.), John Wiley and Sons, Inc., New York (1966).

25. R. S. Voge1 and L. A. Ferguson, Rev. Sci. Instrum. 37, 934 (1966);

L. A. Ferguson, Rev. Sci. Instrum. 37, 964 (1.966).

26. R. W. Hendricks, Rev. Sci. Instrum. 40, 1216 (1969). 
THIS PAGE

\section{WAS INTENTIONALLY \\ LEFT BLANK}


APPENDIX I

Electronic Determination of Spatial Resolution

The spatial resolution of the detector can be adjusted as follows. With a radioactive source illuminating the detector, obtain a trace of the bipolar output pulse from the main amplifier at either end of the anode wire, as illustrated in Fig. 27. Measure the noise level (N) in rms volts with an RMS voltmeter with ov bias. Apply the bias voltage and determine the slope of the pulse at crossover $\left(\mathrm{S}_{c}\right)$ in volts/time. Also determine the sensitivity of the detector $\left(S_{D}\right)$ in time/length as the product of the multichannel analyzer conversion factor (channels/length) as in Fig. 9 (p. 13, this report) multiplied by the delay time per channel (time/channel). (The latter may be determined by changing the delay on the single channel analyzer and observing how many channels a given peak in the scattering pattern is moved.) The spatial resolution, $R$, is then

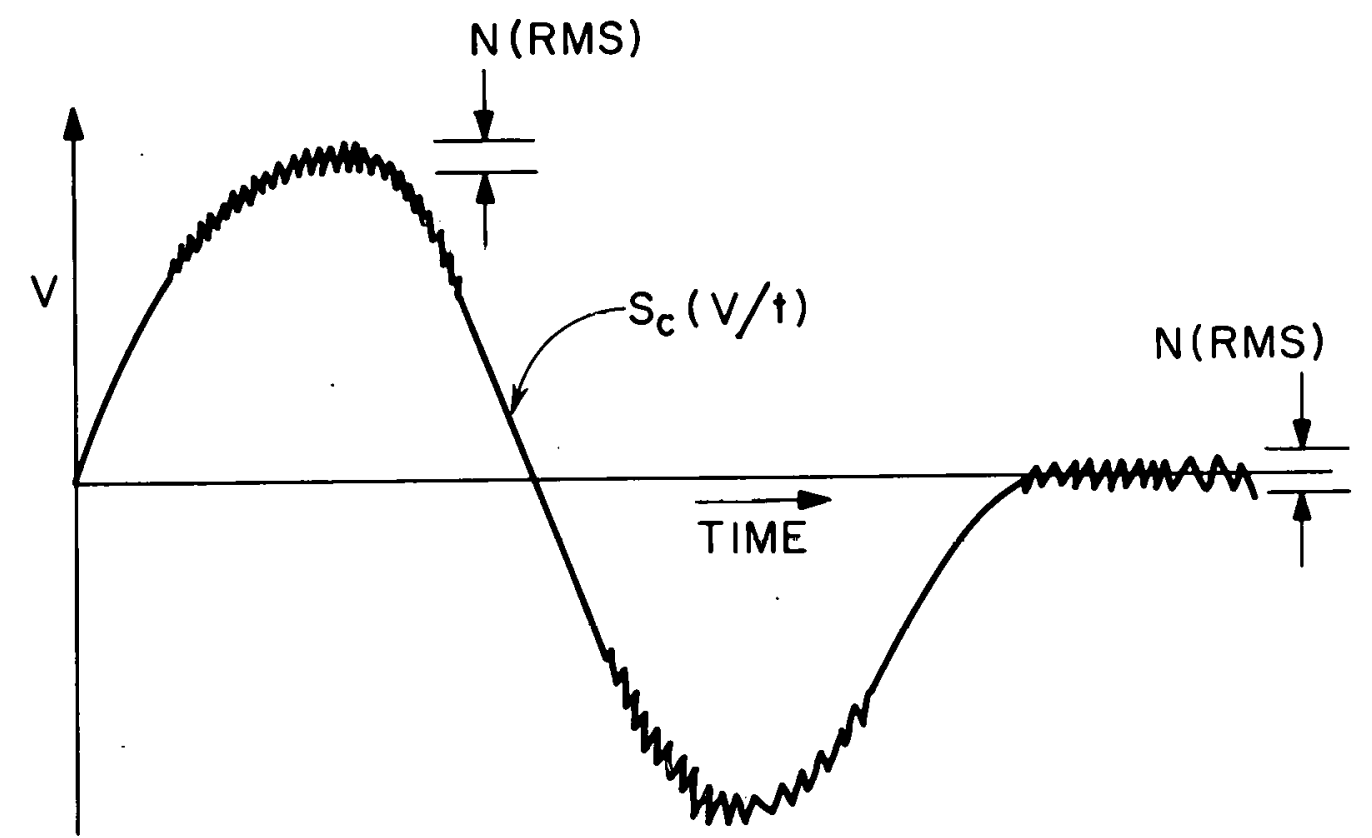

Fig. 27. Schematic of pulse shape from main amplifier at either end of detector wire. 


$$
R(R M S)=\frac{1}{S_{C}} \cdot N \cdot \frac{1}{S_{D}}
$$

For the detector described in this report (at bias $=-2600 \mathrm{~V}$ )

$$
\begin{aligned}
\mathrm{N} & \cong 1 \mathrm{mV}, \\
\mathrm{S}_{\mathrm{D}} & \approx 12 \mathrm{~ns} / \mathrm{mm}, \\
\mathrm{S}_{\mathrm{C}} & \approx 0.4 \mathrm{~V} / \mathrm{\mu s}, \text { and } \\
\mathrm{R} & \cong 0.2 \mathrm{~mm} \text { (RMS) or } 0.5 \mathrm{~mm} \mathrm{FWHM*}
\end{aligned}
$$

Increase the bias voltage until the slope has increased sufficiently to achieve the desired value of $R$.

\footnotetext{
${ }^{*}$ FWHM $=2.35 \sigma$.
} 
ORNL/TM- 6678

INTERNAL DISTRIBUTION

$\begin{aligned} & \text { 1-2. } \text { Central Research Library } \\ & 3 . \text { Document Reference Section } \\ & \text { 4-5. Laboratory Records Department } \\ & 6 . \\ & \text { 7. Laboratory Records, ORNL RC } \\ & \text { 8. } \text { R. K. Abele } \\ & \text { 9. B. S. Borie } \\ & \text { 10-59. R. W. Hendricks } \\ & 60 . \text { H. N. Hill } \\ & 61 . \text { M. R. Hill } \\ & 62 . \text { W. C. Koehler }\end{aligned}$
63.
M. K. Kopp
64-65. J. S. Lin
66. C. J. McHargue
67. C. H. Nowlin
68. H. Postma
69. D. B. Trauger
70. J. R. Weir, Jr.
71. M. K. Wilkinson
72. H. L. Yakel
73. R. E. Zedler
74. A. Zucker

\section{EXTERNAL DISTRIBUTION}

75. Geoffrey Allen, Imperial College, London

76. B. W. Batterman, Cornell University, I thaca, NY

77. R. F. Bonart, Universität Regensburg, Regensburg, Germany

78. S. Bram, University of California, Berkeley, CA

79. H. Brumberger, Syracuse University, Syracuse, NY

80. S. L. Cooper, University of Wisconsin, Madison, WI

81. B. Crist, Northwestern University, Evanston, IL

82. C. R. Desper, Army Materials E Mechanics Research Center, Watertown, MA

83. E. W. Fischer, Universität Mainz, Mainz, Germany

84. P. J. Flory, Stanford University, Stanford, CA

85. R. W. Gould, University of Florida, Gainesville, FL

86. I. R. Harrison, Pennsylvania State University, University Park, PA

87. T. Hashimoto, Kyoto University, Kyoto, Japan

88. J. S. Higgins, Imperial College, London, England

89. L. C. Ianniello, Department of Energy, Washington, DC

90. F. Kelley, University of Akron, Akron, OH

91. F. A. Khoury, National Bureau of Standards, Washingtón, DC

92. J. Koberstein, University of Massachusetts, Amherst, MA

93. 0. Kratky, University of Graz, Graz, Austria

94. P. Krautwasser, Kernforschungsanlage, Jülich, Germany

95-96. C. Macoskv, University of Minnesota, Minneapolis, MN

97. D. L. Mitchell, National Science Foundation, Washington, DC

98. L. H. Nosanow, National Science Foundation, Washington, DC

99. Z. Ophir, Virginia Polytechnic Institute, Blacksburg, VA

100. J. F. Reardon, Boston State College, Boston, MA

101. E. J. Roche, CENG, Grenoble, France

102. R. J. Roe, University of Cincinnati, Cincinnati, $\mathrm{OH}$

103. W. Ruland, Universität Marburg, Marburg, Germany

104-113. T. P. Russel1, University of Massachusetts, Amherst, MA

114. D. W. Schaeffer, Sandia Laboratories, Albuquerque, NM

115. J. Schelten, Kernforschungsanlage, Jülich, Germany

116. P. W. Schmidt, University of Missouri, Columbia, MO 
117. B. P. Schoenborn, Brookhaven National Laboratory, Upton, NY

118. J. M. Schultz, University of Delaware, Newark, DE

119. Y. Shindo, Fukui University, Fukui, Japan

120. C. G. Shuil, Massachusetts Institute of Technology, Cambridge, MA

121-125. R. S. Stein, University of Massachusetts, Amherst, MA

126. D. K. Stevens, Department of Energy, Washington, DC

127. C. G. Vonk, Centraal Laboratorium Staatsmijnen, Geleen, Netherlands

128. M. Wai, University of Massachusetts, Amherst, MA

129. F. Warner, Polymer Laboratories, Ltd., Shrewsbury, England

130-131. A. Wasiak, Polish Academy of Sciences, Warsaw, Poland

132. R. Wetton, Loughborough University, Loughborough, UK

133. C. A. Wert, University of Illinois, Urbana, IL

134. G. L. Wilkes, Virginia Polytechnic Institute, Blacksburg, VA

135. A. Wohlpart, Oak Ridge Associated Universities, Oak Ridge, TN

136-162. Technical Information Center

163. Assistant Manager, Energy Research and Development, Department of Energy, Oak Ridge Operations 